\title{
Platelet Activation In Situ in Breasts at High Risk of Cancer: Relationship with Mammographic Density and Estradiol
}

Sofija Mijic and Charlotta Dabrosin

The self-archived postprint version of this journal article is available at Linköping University Institutional Repository (DiVA):

http://urn.kb.se/resolve?urn=urn:nbn:se:liu:diva-175430

N.B.: When citing this work, cite the original publication.

Mijic, S., Dabrosin, C., (2021), Platelet Activation In Situ in Breasts at High Risk of Cancer:

Relationship with Mammographic Density and Estradiol, Journal of Clinical Endocrinology and Metabolism, 106(2), 485-500. https://doi.org/10.1210/clinem/dgaa820

Original publication available at:

https://doi.org/10.1210/clinem/dgaa820

Copyright: Endocrine Society

https://www.endocrine.org/ 


\section{Platelet activation in situ in breasts at high risk of cancer: relationship with}

2 mammographic density and estradiol

$3 \quad{ }^{1}$ Sofija Mijic and ${ }^{* 1}$ Charlotta Dabrosin

$4 \quad{ }^{1}$ Department of Oncology and Department of Biomedical and Clinical Sciences, Linköping

$5 \quad$ University, Linköping, Sweden

6 Short title: Platelet activation in breast tissue

7 Keywords: microdialysis, mammary gland, inflammation, mammography

8 "Corresponding author:

9 Charlotta Dabrosin, MD PhD

10 Professor of Oncology

11 Linköping University

12 Division of Oncology

13 SE-581 85 Linköping, Sweden

14 Phone: +4613286711

16 Funding: This work was supported by grants to C.D. from the Swedish Cancer Society 17 (2018/464), the Swedish Research Council (2018-02584), LiU-Cancer, and ALF of Linköping 18 University Hospital.

19

20 Disclosure: None of the authors have any financial, commercial or other conflicts of interest to 21 disclose. 


\section{Abstract}

CONTEXT: High mammographic density in postmenopausal women is an independent risk factor for breast cancer by undetermined mechanisms. No preventive therapy for this risk group is available. Activated platelets release growth factors that modulate the microenvironment into a pro-tumorigenic state. Estrogens may affect the risk of breast cancer and platelet function. Whether platelets are activated in situ in breast cancer or in normal breast tissue at high risk of breast cancer and the association to estradiol remains elusive.

OBJECTIVE: To investigate whether platelets are activated in situ in breast cancers and in dense breast tissue of postmenopausal women and explore correlations between estradiol, released platelet factors, and inflammatory proteins.

SETTING AND DESIGN: Sampling of in vivo proteins was performed using microdialysis in a total of 71 women; 10 with breast cancer, 42 healthy postmenopausal women with different breast densities, and 19 premenopausal women.

RESULTS: Our data demonstrate increased levels of coagulation factors in dense breast tissue similar to that found in breast cancers, indicating excessive platelet activation. Premenopausal breasts exhibited similar levels of coagulation factors as postmenopausal dense breasts. Out of 13 coagulations factors that were upregulated in dense breasts, 5 exhibited significant correlations with estradiol both locally in the breast and systemically. In breast tissue, positive correlations between coagulation factors and key inflammatory proteins and matrix metalloproteinases were detected.

CONCLUSIONS: Breast density, not estradiol, is the major determinant of local platelet activation. Inactivation of platelets may be a therapeutic strategy for cancer prevention in postmenopausal women with dense breasts. 


\section{Introduction}

Platelets have dynamic biological roles in a wide range of pathophysiological events including wound healing and cancer progression (1). Inflammation, increased cell proliferation, extracellular matrix $(\mathrm{ECM})$ remodelling and migration are fundamental features of the wound healing process and hallmarks of cancer (2). Activated platelets may contribute to primary cancer growth via release of growth factors in the local microenvironment. When platelets adhere to defects in the endothelial lining of vessel walls, they are activated and aggregate to form a primary hemostatic plug and the coagulation cascade is initiated. This physiological process is tightly regulated to prevent thrombogenic complications. The activated platelets secrete a plethora of proteins, including pro-inflammatory and angiogenic factors, that modify the tissue microenvironment and provide proper "soil" for cancer growth (3). Tightly intertwined crosstalk occurs between the hemostatic and inflammatory systems; proinflammatory proteins trigger the hemostatic system, including platelet activation, which releases additional pro-inflammatory cytokines leading to recruitment of immune cells into the tissue that exacerbate inflammation (4). During inflammation and platelet activation, several pro-angiogenic proteins are released that contribute to increased vascular leakiness and increased angiogenesis, including platelet-derived growth factors (PDGFs), vascular endothelial growth factor (VEGF), and matrix metalloproteinases (MMPs) (5-7). Although it is well known that cancer patients display elevated platelet counts and are prone to thrombotic events and that platelets contribute to metastatic spread (8), the role of activated platelets during the early steps of carcinogenesis remains unknown. Estradiol may affect hemostasis via effects on platelet function, as well as affecting the liver production of several coagulation factors $(9,10)$. Additionally, cumulative exposure to sex steroids including estradiol is an established risk factor for breast cancer but the exact biological mechanisms remain undetermined (11). 
Another major independent risk factor for breast cancer is increased

mammographic density (12). Women with $>50 \%$ dense area of the breasts have a $4-6$ fold increased risk of breast cancer compared to women with $<10 \%$ dense area (12). Additionally, the absolute amount of nondense area is independently and inversely associated with breast cancer risk (13). Although it has been suggested that women with $>50 \%$ dense area comprise $30 \%$ of all breast cancer cases $(12,14)$, there are no specific preventive measures available for these women. While the epidemiological evidence is compelling, very little is known about the biological differences between dense and nondense breast tissues, which is necessary to identify novel preventive therapeutics. Recent studies suggest that dense breast tissue is associated with an altered metabolic profile and an inflammatory microenvironment similar to that found in breast cancer (15-18). Activation of the hemostatic system, including platelet activation, is a well-known systemic trait in cancer patients, including breast cancer patients (19). Whether and how the hemostatic system is activated in vivo in the microenvironment human breast cancer microenvironment and in normal breast tissues at high risk of cancer i.e. dense breast tissue in postmenopausal women and the possible relationship with estradiol remains unknown.

Here, we present new evidence suggesting that dense breast tissue in postmenopausal women, which has inherently high risk of breast cancer, was associated with increased platelet activation in situ similar to that found in established breast cancers. Several components of the hemostatic system correlated significantly with key inflammatory proteins and MMPs in the breast. Whereas estradiol affected some of the coagulation factors, breast density seems to play a more prominent role for the local control of coagulation and platelet activation. Our results provide novel biological understanding of the microenvironment of dense breast tissue and identify platelet activation as a new potential molecular target for the prevention of breast cancer in postmenopausal women with dense breast tissue. 
Subjects

The Regional Ethical Review Board of Linköping, Sweden approved this study,

which was carried out in accordance with the Declaration of Helsinki. All subjects gave informed consent. Forty-two healthy postmenopausal women (ages 55-74 years) were consecutively recruited during their regular mammography screening at Linköping University Hospital. The screening mammograms were categorized according to the Breast Imaging Reporting and Data System (BI-RADS) density scale as either entirely fatty non-dense (BIRADS A) or extremely dense (BI-RADS D) (20). After re-evaluation of the mammograms one woman in each group were miss-categorized and therefore excluded from the group-wise comparisons between dense and nondense groups but included in the correlation analyses. Additionally, 19 nulliparous premenopausal women (ages 20-32 years) with a history of regular menstrual cycles (cycle length, 27-34 days) were investigated the luteal phases of the menstrual cycle. None of the healthy volunteer women had a history of breast cancer. breast cancer were recruited and investigated before surgery. All of the cancers were estrogenand progesterone receptor positive and HER-2 receptor negative, the tumor size ranged from 19-60 mm, and the Nottingham histological grades were 2 or 3 according to the Elston Ellis scoring system determined at the Department of Pathology and Cytology, University Hospital

115 of Linköping. Nine of the women were free of axillary metastases and one woman had a positive 116 sentinel node.

Importantly, none of the women were currently using (or had used within the past 1183 months) any sex steroid containing drugs or implants, such as hormone replacement therapy, 119 sex steroid containing contraceptives, or anti-estrogen therapies, such as selective estrogen 120 receptor modulators or degraders. 


\section{Microdialysis Procedure}

Microdialysis was been performed as previously described (17,18,21-23). In brief, $0.5 \mathrm{~mL}$ lidocaine $(10 \mathrm{mg} / \mathrm{mL})$ was administrated intracutaneously prior the insertion of the microdialysis catheters. The microdialysis catheter (71/M Dialysis AB, Stockholm, Sweden) consisting of a tubular dialysis membrane (diameter $0.52 \mathrm{~mm}, 100,000$ atomic mass cut-off) glued to the end of a double-lumen tube ( $80 \mathrm{~mm}$ long $\times 0.8 \mathrm{~mm}$ in diameter), was inserted via a splitable introducer (M Dialysis $A B)$ connected to a microinfusion pump (M Dialysis $\mathrm{AB}$ ) and perfused with $154 \mathrm{mmol} / \mathrm{L} \mathrm{NaCl}$ and $60 \mathrm{~g} / \mathrm{L}$ hydroxyethyl starch (Voluven ${ }^{\circledR}$, Fresenius Kabi, Uppsala, Sweden) at a perfusion rate of $0.5 \mu \mathrm{L} / \mathrm{min}$. In the healthy postmenopausal women with various breast densities and in the premenopausal women, $20 \mathrm{~mm}$ long microdialysis membranes were placed in the upper lateral quadrant of the left breast directed towards the nipple. In the women with breast cancer, microdialysis catheters with a 10 $\mathrm{mm}$ long membrane were inserted within the breast cancer tissue and another one was inserted within adjacent normal breast tissue. After a 60 min equilibration period, the outgoing perfusate was stored at $-80^{\circ} \mathrm{C}$ for subsequent analysis.

\section{Protein quantification}

The microdialysis samples were analyzed using a multiplex proximity extension assay (PEA, Olink Bioscience, Uppsala Sweden). Briefly, $1 \mu \mathrm{L}$ sample was incubated with antibody pairs tagged with DNA reporter molecules. Once the pair of antibodies was bound to their corresponding antigens, the respective DNA tails formed an amplicon by proximity extension, which was quantified by high-throughput real-time PCR (BioMark ${ }^{\mathrm{TM}}$ HD System, Fluidigm Corporation, South San Francisco, CA, USA). The generated fluorescent signal correlated directly with protein abundance. The output from the Proseek Multiplex protocol was correlated to quantitation cycles $(\mathrm{Cq})$ by the BioMark's Real-Time PCR Software. To minimize variation within and between runs, the data were normalized using both an internal 
146

147

148

149

150

151 be made.

152

154

155

156

157

158

159

160

161

162

163

164

165

166

167

168

169 Estradiol

\section{Estradiol}

control (extension control) and an interplate control and were subsequently transformed using a pre-determined correction factor. The pre-processed data were provided as arbitrary unit normalized protein expressions (NPX) on a $\log _{2}$ scale and were then linearized using the $2^{\mathrm{NPX}}$ formula. A high NPX value corresponded to a high protein concentration. The values were relative quantifications, thus no comparisons of absolute levels of the different proteins could

Estradiol levels in the microdialysis samples were analyzed using a high sensitivity immunoassay kit (DRG International, Springfield Township, NJ, USA).

\section{Platelet preparation and analyses}

Blood was collected into vacutainers containing acid-citrate-dextrose (ACD-A vacuette tube, Greiner Bio-One, Kremsmünster, Austria) and centrifuged to obtain platelet rich plasma (PRP), which was diluted in HEP buffer (140 mM NaCl, 2.7 mM KCl, 3.8 mM HEPES, $5 \mathrm{mM}$ EGTA) containing $1 \mu \mathrm{M}$ prostaglandin-E1 (Sigma-Aldrich, MO, USA) to prevent platelet activation. PRP was centrifuged and platelet pellets were carefully washed in $10 \mathrm{mM}$ sodium citrate, $150 \mathrm{mM} \mathrm{NaCl}, 1 \mathrm{mM}$ EDTA and 1\% dextrose. Platelets resuspended in Tyrode's buffer (134 mM NaCl, 12 mM NaHCO $3,2.9$ mM KCl, 0.34 mM Na $2 \mathrm{HPO}_{4}, 1 \mathrm{mM}$ $\mathrm{MgCl}_{2}, 10 \mathrm{mM}$ HEPES) containing $5 \mathrm{mM}$ glucose and $3 \mathrm{mg} / \mathrm{ml}$ of bovine serum albumin were seeded in $96 \mathrm{U}$-shaped well plates at $1.8 \times 10^{7}$ cells/well and preincubated at $37^{\circ} \mathrm{C}$ for $10 \mathrm{~min}$ with $1 \mathrm{nM}$ 17- $\beta$-estradiol (E2) (Sigma-Aldrich, MO, USA) $\pm 10 \mathrm{nM}$ progesterone (SigmaAldrich, MO, USA) or left untreated. Thereafter, $0.1 \mathrm{U} / \mathrm{ml}$ thrombin (Sigma-Aldrich) was added for $10 \mathrm{~min}$ at $37^{\circ} \mathrm{C}$. Plates were centrifuged at $+4^{\circ} \mathrm{C}$ and supernatants were frozen for subsequent ELISA assays; u-plasminogen activator/urokinase (uPA), soluble uPA receptor (suPAR) and plasminogen activator inhibitor-1 (PAI) (R\&D Systems Inc. Minneapolis, USA) 
170 and serine protease inhibitor 5 (SERPINA5) (RayBiotech Peachtree Corners, GA, USA)

171 performed according to manufactures instructions.

172 Statistical analyses

173 Statistical analyses were performed using nonparametric Wilcoxon matched-pairs

174 signed rank tests or Kruskal Wallis tests followed by unpaired Mann-Whitney U tests when

175 more than two groups were compared as the data was non-normally distributed. Correlations

176 were analyzed using Spearman's correlation test. All tests were two-sided. A $P<0.05$ was

177 considered statistically significant. Statistics were performed with Prism 8.0 (GraphPad, San

178 Diego, CA, USA).

179

180

181

182

183

184

185

186

187

188 
No difference in local estradiol levels in postmenopausal women with dense or nondense breast tissue

No significant difference was detected of local estradiol levels in breast tissue, median (25-75 percentiles), between postmenopausal women with dense or nondense breasts; $38 \mathrm{pmol} / 1$ (28-48) vs. $37 \mathrm{pmol} / 1$ (34-44) respectively. The levels in breast tissue of premenopausal women were $205 \mathrm{pmol} / 1$ (170-234). Similarly, no significant difference was detected of local estradiol levels in abdominal subcutaneous fat, median (25-75 percentiles), between postmenopausal women with dense or nondense breasts; 38 pmol/1 (31-49) vs. 36 pmol/1 (35-46) respectively. The levels in abdominal subcutaneous fat of premenopausal women were $202 \mathrm{pmol} / \mathrm{l}(155-235)$.

Breast cancer, dense breast tissue in postmenopausal women, and premenopausal breasts tissue display markers of platelet activation in situ

Platelet activation is driven by different pathways stimulated by agonists, such as von Willebrand factor (VWF). In normal hemostasis, VWF is released by endothelial cells to initiate platelet activation and, subsequently, by alpha granules of activated platelets themselves. Significantly increased levels of extracellular VWF were observed in breast cancer and dense breast tissues (Figure 1A). Premenopausal breast levels of VWF were similar to those found in dense breasts. Thrombin is a potent platelet agonist that binds and cleaves the extracellular domain of protease-activated receptors (PARs) during platelet activation. Levels of secreted PAR1 were significantly higher in breast cancer tissue than in adjacent normal breast tissue and in dense breast tissue than in nondense breast tissue. Premenopausal breasts exhibited similar levels as dense breasts (Figure 1B). Several other proteins, including P-selectin, CD40 ligand (CD40L), and platelet-derived growth factor subunits A (PDGFA) and B (PDGFB) are associated with platelet activation. Expression of all of these markers was significantly higher 
214 in breast cancer tissue than in normal tissue and higher in dense breast tissue than in nondense

215 breast tissue (Figure 1C-F). With the exception of PDGFB all of these proteins were similar in 216 premenopausal breast tissues and postmenopausal dense breasts.

217 Enhanced activation of the coagulation system in breast cancer, dense breasts in 218 postmenopausal women, and premenopausal breasts tissue

As a consequence of the initial platelet adhesion and activation, the coagulation cascade is triggered. The coagulation cascade can be activated via the intrinsic and/or the extrinsic pathway that ultimately converge on the activation of Factor X (FX) (24). The extrinsic pathway is initiated by tissue injury when Factor VII (FVII) leaves circulation and accumulates in the tissue, whereas the intrinsic (contact) pathway is triggered by Factor XI (FXI). Our data showed significantly increased levels of FVII and FXI in breast cancer tissue indicating activation of both the intrinsic and the extrinsic coagulation pathways (Figure 2AB). There was a three-fold increase in extracellular levels of FVII in dense breast tissue when compared with nondense breast tissue, whereas there was no difference in the FXI level suggesting that the extrinsic pathway but not the intrinsic pathway is activated in dense breasts (Figure 2A-B). In premenopausal breasts the levels of FVII were similar to those detected in postmenopausal dense breasts whereas no differences were found in FXI levels (Figure 2A-B).

Activation of anticoagulant mechanisms in breast cancer, dense breasts in postmenopausal women, and premenopausal breasts tissue

233 During activation of the coagulation cascade, levels of many anticoagulant proteins also 234 increase to maintain the hemostatic balance. Protein C (PROC) controls blood coagulation by 235 inhibiting FV and FVII. PROC activity is regulated by plasma serine protease inhibitor 5 236 (SERPINA5), which has both pro- and anti-coagulation activities, and by the tissue factor 237 pathway inhibitor (TFPI), which also controls tissue factor (TF) activity. All of these proteins 238 were significantly upregulated in breast cancer and dense breast tissues (Figure 3A-C). In 
premenopausal breasts the levels of PROC and TFPI were significantly increased as compared

240 to both dense and nondense breasts in postmenopausal women. SERPINA5, on the other hand,

241 was significantly lower compared to dense and nondense breasts in postmenopausal women

242 (Figure 3A-C).

Fibrinolysis, another key step in coagulation, limits the activity of the coagulation

244 cascade by dissolving blood clots via plasmin and thus inhibits excess thrombotic formations.

245 Plasmin is generated from plasminogen by tissue-type plasminogen activator (tPA) and 246 urokinase-type plasminogen activator (uPA) and its generation is inhibited by plasminogen 247 activator inhibitor-1 (PAI). Although tPA levels did not differ in breast cancer vs. normal and 248 in dense breast vs. nondense breast tissues or premenopausal breasts (Figure 3D), both uPA and 249 PAI levels were significantly higher in breast cancer and dense breast tissues (Figure 3E-F). In 250 premenopausal breasts, the uPA levels were significantly higher than in both dense and 251 nondense postmenopausal breasts, whereas the levels of PAI in premenopausal breast were 252 comparable to postmenopausal dense breasts (Figure 3E-F).

The soluble form of the urokinase plasminogen activator receptor (suPAR) has 254 also been shown to increase lysis of fibrin clots (25). Consistently, secretion of suPAR was 255 significantly increased in both breast cancer and dense breast tissue. Premenopausal breasts 256 exhibited similar levels as in dense postmenopausal breasts (Figure 3G).

Correlations between coagulation factors and inflammatory and angiogenic proteins in the

\section{normal breast tissue microenvironment}

Comparative studies have shown that various steps of hemostasis and immunity

260 are co-regulated and intertwined in cancerous tissue and during injury. Whether this 261 relationship is present in normal tissue is unknown. To test this hypothesis, we evaluated 262 associations between the pro-inflammatory cytokines and angiogenic proteins IL-6, IL-8, TGF$263 \beta$, and VEGF and hemostatic biomarkers in normal breast tissue. Our data demonstrated that 
IL-6, TGF- $\beta$, and VEGF correlated positively with all hemostatic proteins except SERPINA5 and tPA. IL-8 levels also correlated positively with levels of the hemostatic factors with the few exceptions of SERPINA5, tPA, FXI, SELP, and PDGFB (Figure 4).

Correlations between coagulation factors and MMPs in the normal breast tissue microenvironment

Another group of platelet-derived molecules that control the tissue

microenvironment are MMPs. Platelets contain and release several MMPs, including MMP-1, MMP-2, MMP-3, and MMP-9 (7). Additionally, platelets may enhance the secretion of MMPs from immune cells in the microenvironment (26). As shown in Figure 5, significant correlations were found between MMP-1,-2, -3 , and -9 and the majority of coagulations factors.

Correlations between coagulation factors and estradiol levels locally in abdominal subcutaneous fat and in breast tissue

Finally, we investigated whether the findings in dense breast tissue were a result of local events in the breast microenvironment or an inherently systemic difference between the women. Microdialysis was therefore performed in abdominal subcutaneous fat also. As shown in Table 1, the levels of UPA, PAI, suPAR, SERPINA5, and PROC were significantly altered in abdominal subcutaneous fat of premenopausal women whereas there were no differences in fat tissue between the two groups of postmenopausal women. This led us to investigate whether estradiol was involved in the regulation of these factors. Indeed, we found that in abdominal

283 subcutaneous fat, local levels of estradiol correlated significantly with these five factors (Figure 284 6A). In breast tissue these five proteins, and in addition TFPI, also correlated significantly with 285 local breast estradiol levels (Figure 6B).

286 Sex steroids may affect platelet phenotypes both by genomic effects on bone marrow derived 287 megacaryocytes and by non-genomic effect directly on platelets, which lack cell nucleus. To 288 elucidate whether estradiol alone or in presence of progesterone affected platelets per se, 
289 platelets were exposed to the hormones in vitro. Of the five proteins that correlated with 290 estradiol uPA, PAI, suPAR, SERPINA5 may be release by platelets in the tissue whereas PROC 291 is mainly produced in the liver. As shown in Figure 6C the release of suPAR increased and 292 SERPINA5 decreased after estradiol exposure whereas progesterone had no additional effects 293 on platelet function. These results corroborate the in vivo data. uPA was below the detection 294 limit and PAI was unaltered after hormone exposure.

295 Sustained coagulation-inflammation loop in dense breast tissue In figure 7 the results are summarized in a graphical abstract. 
Although a high mammographic density is an established independent risk factor

299 for breast cancer, the molecular mechanisms underlying this risk has not yet been determined.

300 More knowledge is required to design preventive therapeutic interventions. In this study, we 301 found that, similar to breast cancers, dense breast tissue displayed platelet activation and 302 upregulation of coagulation and fibrinolysis pathway components. Indeed, dense breast tissue 303 in postmenopausal women exhibited similar levels of the factors as premenopausal breasts. 304 Some of the factors correlated with estradiol both systemically and locally in the breast but 305 breast density was the major determinant for the regulation of the proteins. To the best of our 306 knowledge, this is the first report showing similar in vivo coagulation factor profiles in dense 307 breasts and breast cancers.

308 Increased coagulation has been associated with cancer since 1865 when an association of excessive blood coagulation and cancer progression was described (27). Additionally, numerous studies have shown that plasma levels of different platelet activation biomarkers and

311 coagulation factors, such as soluble P-selectin, soluble CD40L, and VWF, are significantly 312 higher in cancer patients, including breast cancer patients, suggesting that coagulation systems 313 are activated during cancer progression (28-31). Platelets may also sustain tumor dissemination 314 by protecting tumor cells in the circulation from the normal immune response, thus increasing 315 the metastatic capacity of cancer cells (32). Previous studies have primarily described the 316 systemic coagulation effects, rather than the local mechanisms, during cancer progression. 317 Experimental studies have revealed that platelets create a microenvironment supportive of 318 cancer cell survival by secreting a plethora of cytokines, chemokines, ECM remodeling 319 proteases, growth and angiogenic factors (26), however, how these proteins are released in 320 human cancers in vivo is undetermined. Indeed, our data corroborate previous experimental 321 results and systemic effects; the local breast cancer microenvironment exhibited protein levels 322 suggestive of platelet activation and induction of coagulation. Additionally, anticoagulant 
323 factors, including components of fibrinolysis, were also higher in the breast cancer 324 microenvironment. Interestingly, the uPA level was higher, whereas the tPA level was unaltered

325 in the breast cancers. We interpret this as a consequence of tPA primarily being involved in 326 blood clotting in the systemic circulation, whereas uPA is important for local remodeling of the 327 ECM (33). Here, we report striking similarities of platelet activation and coagulation between 328 the microenvironment of breast cancers and the microenvironment of healthy dense breast tissue. Similar to the breast cancer microenvironment, dense breast tissue exhibited increased levels of VWF, PAR1, P-selectin, CD40L, PDGFA, PDGFB, FVII, SERPINA5, TFPI, PROC, 331 uPA, suPAR, and PAI whereas FXI was unaffected in dense breasts but up-regulated in breast 332 cancer.

333 Coagulopathy may be related to estrogen therapies; the risk of thromboembolism seems to be 334 increased with oral preparations rather than other routes of administration due to the first 335 passage effect on liver function (10). How endogenous estradiol affects the coagulation system 336 is elusive. Our present data suggests that estradiol may indeed affect suPAR, uPA, PAI, PROC, 337 and SERPINA5 as the levels of these proteins correlated significantly with estradiol both locally 338 in the breast and in abdominal subcutaneous fat, which we interpret as systemic effects. 339 Increased plasma levels of suPAR in women compared with men has recently been reported 340 corroborating our results (34). PROC, which is produced in the liver, exhibited significant 341 correlations with estradiol suggesting hormonal liver effects. Interestingly, our data revealed a 342 significant negative correlation with estradiol and SERPINA5, which is mainly produced in the 343 liver in women and in male genitalia. The majority of the coagulation factors were increased in 344 premenopausal breasts but unrelated to estradiol. Thus, breast density per se seems to be more 345 important than hormone levels for the regulation of coagulation factors in the breast 346 microenvironment. This is supported by several studies showing that, after adjustments of body 347 mass index, endogenous levels of estrogens, androgens, progesterone, and prolactin lack 
association with mammographic breast density $(12,35)$. Regarding exogenous hormones, the combination of estrogens (E) and progestins (P) to postmenopausal women seems to be associated with increased mammographic density compared to E only therapy (36). However, while the combined therapy of $\mathrm{E}+\mathrm{P}$ is associated with increased risk of estrogen receptor positive $(\mathrm{ER}+)$ breast cancer, high mammographic density has mainly been associated with equal risk of both ER+ and ER- breast cancer in postmenopausal women and with ER- breast 354 cancer in premenopausal women (37). Additionally, other steroid hormone signaling pathways 355 may also affect the breast cancer progression; activation of the glucocorticoid receptor (GR) may increase ER- breast cancer progression whereas GR expression in ER+ breast cancer may improve progression free survival $(38,39)$. A link between GR and inflammatory pathways via

358 TGF- $\beta$ has also been demonstrated in ER- breast cancer (39). How glucocorticoids and/or GR 359 affect breast density is yet to be determined.

360 Premenopausal women have high mammographic breast density and the normal physiological 361 process after menopause is an involution with loss of glandular tissue, which is replaced with 362 adipose tissue resulting in decreased mammographic density (40-42). Why or how this process 363 is halted in some women is elusive. One reason may be that a stiff extracellular 364 microenvironment affects the activation of the estrogen receptor including ligand-independent 365 actions, thereby sustaining the expression of proteins that were induced by previous estradiol 366 exposure $(43,44)$. This supports our results suggesting that breast density per se plays a more 367 critical role than estradiol exposure for the local activation of platelets and coagulation. In contrast with breast cancers, only components of the extrinsic pathway were 369 upregulated in dense breasts indicating that platelet activation and coagulation is initiated by 370 external stimuli, such as increased tissue pressure induced by dense collagen (45). Indeed, it 371 has been demonstrated that mechanical properties may affect platelet function; platelets can 372 mechanosense the stiffness of the underlying fibrin/fibrinogen substrate leading to increased 
373 platelet activation and adhesion that enhances pro-coagulant activity (46). Additionally, 374 components of the immune system are sensitive to changes in the ECM, for example, 375 macrophages grown on stiff substrates produce more proinflammatory mediators than 376 macrophages cultured on soft substrates, and many ECM proteins contain cryptic domains that 377 affect immune and pro-inflammatory cell behavior (47-49). Previous data indicate that 378 mammographic dense breast tissue is associated with a local proinflammatory 379 microenvironment including increased levels of VEGF and IL-8 and MMPs (16-18,50,51). 380 These proteins increase vascular permeability, disrupt the endothelial barrier which in turn will 381 expose ECM components, and enhance extravasation of immune cells leading to the 382 recruitment of activated platelets. During activation, platelets release granules containing a 383 plethora of factors that modulate the microenvironment and attract innate immune cells to the 384 site creating a vicious circle (52-57). These interactions have primarily been shown in cancerous 385 tissues, and it has been much less clear whether these interactions are present in normal tissues.

386 Our present data show that this tight interdependent relationship between inflammation, 387 angiogenesis, and hemostasis is also present in normal breast tissue. We hypothesize that breast 388 density itself may trigger the coagulation system to act in concert with the inflammatory cascade 389 creating an inflammation-coagulation cycle resulting in a pro-tumorigenic microenvironment 390 in dense breasts (summarized in Figure 7). Thus, when atypical cells arise in the breast 391 epithelium, the extracellular microenvironment in dense breasts, exhibiting a triggered 392 coagulation system, would be more permissive for continuous expansion and invasion of these 393 cells leading to increased risk of developing clinically significant breast cancer in dense breasts.

394 Our data clearly shows that the changes detected in dense breasts are tissue-specific because no 395 differences were found between the dense breast and nondense breast groups in the extracellular 396 environment of abdominal subcutaneous fat. 
398 inhibits platelet aggregation and activation by inhibiting cyclooxygenase activity (58). Low399 dose aspirin may reduce the incidence of colorectal cancer by one-third, but the effect on breast 400 cancer prevention has been less encouraging (59). In a large population study of women without 401 risk factors, alternate-day low-dose aspirin use did not reduce breast cancer incidence, whereas 402 a small study of women with benign breast disease who reported aspirin use suggested a 403 reduced risk of breast cancer $(60,61)$. Additionally, epidemiological data of women with early 404 stage breast cancer suggested beneficial effects of low-dose aspirin (62). To date, there are no 405 randomized data on low-dose aspirin use as a preventative therapy for women with a high risk of breast cancer. Our data has unraveled a molecular justification for such trials. increased platelet activation in vivo similar to what was detected in human breast cancers. Premenopausal breasts exhibited similar levels of coagulation factors as postmenopausal dense breasts, but the majority of these factors were unrelated to estradiol suggesting that breast

411 density per se is a major determinant for activation of platelets and the coagulation system.

412 Our data revealed significant correlations between inflammatory proteins and coagulation 413 factors supporting intertwined local regulation in normal breast tissue. Targeting platelet activation with aspirin or other pathways in the coagulation system may be a feasible approach to developing preventative therapeutics for women with a high risk of developing breast cancer,

416 such as postmenopausal

\section{Author contributions} CD designed the project and performed all microdialysis investigations. CD and

420 SM analyzed the data and prepared and finally approved the manuscript 


\section{Acknowledgments}

The authors would like to thank Ann-Christine Andersson and Annelie

424 Abrahamsson of the Department of Oncology and Department of Biomedical and Clinical

425 Sciences, Linköping University, for providing excellent technical assistance and Anna

426 Rzepecka MD and the staff of the Mammography Department, Linköping University Hospital,

427 for identifying subjects with different mammographic densities.

428

429 Data availability

430 The data generated during the current study are not publicly available but are available from

431 the corresponding author on reasonable request.

432 


\section{References}

434 1. Asghar S, Parvaiz F, Manzoor S. Multifaceted role of cancer educated platelets in

2. Hanahan D, Weinberg RA. Hallmarks of cancer: the next generation. Cell. 2011;144(5):646-674.

3. Chen M, Geng JG. P-selectin mediates adhesion of leukocytes, platelets, and cancer cells in inflammation, thrombosis, and cancer growth and metastasis. Arch Immunol Ther Exp (Warsz). 2006;54(2):75-84.

4. Levi M, van der Poll T. Inflammation and coagulation. Crit Care Med. 2010;38(2 Suppl):S26-34.

5. Andrae J, Gallini R, Betsholtz C. Role of platelet-derived growth factors in physiology and medicine. Genes Dev. 2008;22(10):1276-1312.

6. Verheul HM, Jorna AS, Hoekman K, Broxterman HJ, Gebbink MF, Pinedo HM. Vascular endothelial growth factor-stimulated endothelial cells promote adhesion and activation of platelets. Blood. 2000;96(13):4216-4221.

7. Seizer P, May AE. Platelets and matrix metalloproteinases. Thromb Haemost. 2013;110(5):903-909.

8. Faria AVS, Andrade SS, Peppelenbosch MP, Ferreira-Halder CV, Fuhler GM. Platelets in aging and cancer-"double-edged sword". Cancer Metastasis Rev. 2020.

9. Dupuis M, Severin S, Noirrit-Esclassan E, Arnal JF, Payrastre B, Valera MC. Effects of Estrogens on Platelets and Megakaryocytes. Int J Mol Sci. 2019;20(12).

10. Straczek C, Oger E, Yon de Jonage-Canonico MB, Plu-Bureau G, Conard J, Meyer G, Alhenc-Gelas M, Levesque H, Trillot N, Barrellier MT, Wahl D, Emmerich J, Scarabin PY, Estrogen, Thromboembolism Risk Study G. Prothrombotic mutations, hormone therapy, and venous thromboembolism among postmenopausal women: impact of the route of estrogen administration. Circulation. 2005;112(22):3495-3500.

11. Collaborative Group on Hormonal Factors in Breast C. Menarche, menopause, and breast cancer risk: individual participant meta-analysis, including 118964 women with breast cancer from 117 epidemiological studies. Lancet Oncol. 2012;13(11):1141-1151.

12. Boyd NF, Martin LJ, Bronskill M, Yaffe MJ, Duric N, Minkin S. Breast tissue composition and susceptibility to breast cancer. J Natl Cancer Inst. 2010;102(16):12241237.

13. Pettersson A, Hankinson SE, Willett WC, Lagiou P, Trichopoulos D, Tamimi RM. Nondense mammographic area and risk of breast cancer. Breast Cancer Res. 2011;13(5):R100.

14. Boyd NF, Guo H, Martin LJ, Sun L, Stone J, Fishell E, Jong RA, Hislop G, Chiarelli A, Minkin S, Yaffe MJ. Mammographic density and the risk and detection of breast cancer. N Engl J Med. 2007;356(3):227-236.

15. Abrahamsson A, Rzepecka A, Dabrosin C. Increased nutrient availability in dense breast tissue of postmenopausal women in vivo. Sci Rep. 2017;7:42733.

16. Huo CW, Chew G, Hill P, Huang D, Ingman W, Hodson L, Brown KA, Magenau A, Allam AH, McGhee E, Timpson P, Henderson MA, Thompson EW, Britt K. High mammographic density is associated with an increase in stromal collagen and immune cells within the mammary epithelium. Breast Cancer Res. 2015;17:79.

17. Abrahamsson A, Rzepecka A, Romu T, Borga M, Leinhard OD, Lundberg P, Kihlberg $\mathrm{J}$, Dabrosin C. Dense breast tissue in postmenopausal women is associated with a proinflammatory microenvironment in vivo. Oncoimmunology. 2016;5(10):e1229723. 
18. Abrahamsson A, Rzepecka A, Dabrosin C. Equal Pro-inflammatory Profiles of CCLs, CXCLs, and Matrix Metalloproteinases in the Extracellular Microenvironment In Vivo in Human Dense Breast Tissue and Breast Cancer. Front Immunol. 2017;8:1994.

19. Lal I, Dittus K, Holmes CE. Platelets, coagulation and fibrinolysis in breast cancer progression. Breast Cancer Res. 2013;15(4):207.

20. Sickles E, D’Orsi C, Bassett L, al. e. ACR BI-RADS ${ }^{\circledR}$ Mammography. In: ACR BIRADS ${ }^{\circledR}$ Atlas, Breast Imaging Reporting and Data System. Reston, VA: American College of Radiology; 2013.

21. Dabrosin C, Hallstrom A, Ungerstedt U, Hammar M. Microdialysis of human breast tissue during the menstrual cycle. Clin Sci (Lond). 1997;92(5):493-496.

22. Garvin S, Dabrosin C. In vivo measurement of tumor estradiol and vascular endothelial growth factor in breast cancer patients. BMC Cancer. 2008;8:73.

23. Dabrosin N, Dabrosin C. Postmenopausal Dense Breasts Maintain Premenopausal Levels of $\mathrm{GH}$ and Insulin-like Growth Factor Binding Proteins in Vivo. J Clin Endocrinol Metab. 2020;105(5).

24. Grover SP, Mackman N. Intrinsic Pathway of Coagulation and Thrombosis. Arterioscler Thromb Vasc Biol. 2019;39(3):331-338.

25. Higazi AA, Bdeir K, Hiss E, Arad S, Kuo A, Barghouti I, Cines DB. Lysis of plasma clots by urokinase-soluble urokinase receptor complexes. Blood. 1998;92(6):20752083.

26. Yan M, Jurasz P. The role of platelets in the tumor microenvironment: From solid tumors to leukemia. Biochim Biophys Acta. 2016;1863(3):392-400.

27. Varki A. Trousseau's syndrome: multiple definitions and multiple mechanisms. Blood. 2007;110(6):1723-1729.

28. Ay C, Pabinger I. Predictive potential of haemostatic biomarkers for venous thromboembolism in cancer patients. Thromb Res. 2012;129 Suppl 1:S6-9.

29. Huang J, Jochems C, Talaie T, Anderson A, Jales A, Tsang KY, Madan RA, Gulley JL, Schlom J. Elevated serum soluble CD40 ligand in cancer patients may play an immunosuppressive role. Blood. 2012;120(15):3030-3038.

30. Yang AJ, Wang M, Wang Y, Cai W, Li Q, Zhao TT, Zhang LH, Houck K, Chen X, Jin YL, Mu JY, Dong JF, Li M. Cancer cell-derived von Willebrand factor enhanced metastasis of gastric adenocarcinoma. Oncogenesis. 2018;7(1):12.

31. Lehrer S, Green S, Dembitzer FR, Rheinstein PH, Rosenzweig KE. Increased RNA Expression of von Willebrand Factor Gene Is Associated With Infiltrating Lobular Breast Cancer and Normal PAM50 Subtype. Cancer Genomics Proteomics. 2019;16(3):147-153.

32. Palacios-Acedo AL, Mege D, Crescence L, Dignat-George F, Dubois C, Panicot-Dubois L. Platelets, Thrombo-Inflammation, and Cancer: Collaborating With the Enemy. Front Immunol. 2019; 10:1805.

33. Smith HW, Marshall CJ. Regulation of cell signalling by uPAR. Nat Rev Mol Cell Biol. 2010;11(1):23-36.

34. Mehta A, Desai SR, Ko YA, Liu C, Dhindsa DS, Nayak A, Hooda A, Martini MA, Ejaz K, Sperling LS, Reiser J, Hayek SS, Quyyumi AA. Sex Differences in Circulating Soluble Urokinase-Type Plasminogen Activator Receptor (suPAR) Levels and Adverse Outcomes in Coronary Artery Disease. J Am Heart Assoc. 2020;9(5):e015457.

35. Tamimi RM, Hankinson SE, Colditz GA, Byrne C. Endogenous sex hormone levels and mammographic density among postmenopausal women. Cancer Epidemiol Biomarkers Prev. 2005;14(11 Pt 1):2641-2647. 
36. Becker S, Kaaks R. Exogenous and endogenous hormones, mammographic density and breast cancer risk: can mammographic density be considered an intermediate marker of risk? Recent Results Cancer Res. 2009;181:135-157.

37. Shieh Y, Scott CG, Jensen MR, Norman AD, Bertrand KA, Pankratz VS, Brandt KR, Visscher DW, Shepherd JA, Tamimi RM, Vachon CM, Kerlikowske K. Body mass index, mammographic density, and breast cancer risk by estrogen receptor subtype. Breast Cancer Res. 2019;21(1):48.

38. West DC, Pan D, Tonsing-Carter EY, Hernandez KM, Pierce CF, Styke SC, Bowie KR, Garcia TI, Kocherginsky M, Conzen SD. GR and ER Coactivation Alters the Expression of Differentiation Genes and Associates with Improved ER+ Breast Cancer Outcome. Mol Cancer Res. 2016;14(8):707-719.

39. Perez Kerkvliet C, Dwyer AR, Diep CH, Oakley RH, Liddle C, Cidlowski JA, Lange CA. Glucocorticoid receptors are required effectors of TGFbetal-induced p38 MAPK signaling to advanced cancer phenotypes in triple-negative breast cancer. Breast Cancer Res. 2020;22(1):39.

40. Russo J, Russo IH. Development of the human breast. Maturitas. 2004;49(1):2-15.

41. Henson DE, Tarone RE. On the possible role of involution in the natural history of breast cancer. Cancer. 1993;71(6 Suppl):2154-2156.

42. Henson DE, Tarone RE. Involution and the etiology of breast cancer. Cancer. 1994;74(1 Suppl):424-429.

43. Ovadia EM, Pradhan L, Sawicki LA, Cowart JE, Huber RE, Polson SW, Chen C, van Golen KL, Ross KE, Wu CH, Kloxin AM. Understanding ER+ Breast Cancer Dormancy Using Bioinspired Synthetic Matrices for Long-Term 3D Culture and Insights into Late Recurrence. Adv Biosyst. 2020:e2000119.

44. Diaz Bessone MI, Gattas MJ, Laporte T, Tanaka M, Simian M. The Tumor Microenvironment as a Regulator of Endocrine Resistance in Breast Cancer. Front Endocrinol (Lausanne). 2019;10:547.

45. Menter DG, Tucker SC, Kopetz S, Sood AK, Crissman JD, Honn KV. Platelets and cancer: a casual or causal relationship: revisited. Cancer Metastasis Rev. 2014;33(1):231-269.

46. Qiu Y, Brown AC, Myers DR, Sakurai Y, Mannino RG, Tran R, Ahn B, Hardy ET, Kee MF, Kumar S, Bao G, Barker TH, Lam WA. Platelet mechanosensing of substrate stiffness during clot formation mediates adhesion, spreading, and activation. Proc Natl Acad Sci U S A. 2014;111(40):14430-14435.

47. Previtera ML, Sengupta A. Substrate Stiffness Regulates Proinflammatory Mediator Production through TLR4 Activity in Macrophages. PLoS One. 2015;10(12):e0145813.

48. Sorokin L. The impact of the extracellular matrix on inflammation. Nature reviews Immunology. 2010;10(10):712-723.

49. Monboisse JC, Oudart JB, Ramont L, Brassart-Pasco S, Maquart FX. Matrikines from basement membrane collagens: a new anti-cancer strategy. Biochim Biophys Acta. 2014;1840(8):2589-2598.

50. Makboon K, Gold EB, Harvey DJ, Butler LM, Habel LA. Association between highsensitivity C-reactive protein (hsCRP) and change in mammographic density over time in the SWAN mammographic density subcohort. Cancer causes \& control : CCC. 2015;26(3):431-442.

51. Lindahl G, Rzepecka A, Dabrosin C. Increased Extracellular Osteopontin Levels in Normal Human Breast Tissue at High Risk of Developing Cancer and Its Association With Inflammatory Biomarkers in situ. Front Oncol. 2019;9:746.

52. Kral JB, Schrottmaier WC, Salzmann M, Assinger A. Platelet Interaction with Innate Immune Cells. Transfus Med Hemother. 2016;43(2):78-88. 
53. Stoiber D, Assinger A. Platelet-Leukocyte Interplay in Cancer Development and Progression. Cells. 2020;9(4).

54. Wallez Y, Huber P. Endothelial adherens and tight junctions in vascular homeostasis, inflammation and angiogenesis. Biochim Biophys Acta. 2008;1778(3):794-809.

55. Chen J, Lopez JA. Interactions of platelets with subendothelium and endothelium. Microcirculation. 2005;12(3):235-246.

56. Pagel O, Walter E, Jurk K, Zahedi RP. Taking the stock of granule cargo: Platelet releasate proteomics. Platelets. 2017;28(2):119-128.

57. Chapin JC, Hajjar KA. Fibrinolysis and the control of blood coagulation. Blood Rev. 2015;29(1):17-24.

58. Burch JW, Stanford N, Majerus PW. Inhibition of platelet prostaglandin synthetase by oral aspirin. J Clin Invest. 1978;61(2):314-319.

59. Cuzick J. Preventive therapy for cancer. Lancet Oncol. 2017;18(8):e472-e482.

60. Cook NR, Lee IM, Zhang SM, Moorthy MV, Buring JE. Alternate-day, low-dose aspirin and cancer risk: long-term observational follow-up of a randomized trial. Ann Intern Med. 2013;159(2):77-85.

61. Gallicchio L, McSorley MA, Newschaffer CJ, Thuita LW, Huang HY, Hoffman SC, Helzlsouer KJ. Nonsteroidal antiinflammatory drugs, cyclooxygenase polymorphisms, and the risk of developing breast carcinoma among women with benign breast disease. Cancer. 2006;106(7):1443-1452.

62. Frisk G, Ekberg S, Lidbrink E, Eloranta S, Sund M, Fredriksson I, Lambe M, Smedby KE. No association between low-dose aspirin use and breast cancer outcomes overall: a Swedish population-based study. Breast Cancer Res. 2018;20(1):142. 


\section{Figure Legends}

Figure 1. Markers of platelets activation are upregulated in breast cancers and in dense breast tissue

A total of 69 women were investigated; 10 breast cancer patients underwent microdialysis before surgery with one catheter inserted into the breast cancer and another into adjacent normal breast tissue and 40 postmenopausal healthy volunteer women, attending the regular mammography-screening program categorized as either having dense ( $\mathrm{n}=20$, dark green bars) or nondense breasts ( $\mathrm{n}=20$, light green bars) and 19 premenopausal women (yellow bars) underwent microdialysis of their left breast. Data represents extracellular local protein abundance in linear values ( $2^{\mathrm{NPX}}$ as described in the Methods section). Kruskal-Wallis followed by Mann Whitney U-test was used for unpaired samples (healthy breast tissues) and Wilcoxon matched-pairs signed-rank for paired samples (breast cancer vs. normal adjacent breast). A. Extracellular local levels of von Willebrand's factor (VWF), B. Extracellular local levels of proteinase-activated receptor 1 (PAR1), C. Extracellular local levels of P-selectin, D. Extracellular local levels of soluble CD40 ligand (CD40L), E. Extracellular local levels of platelet-derived growth factor subunit A (PDGFA), F. Extracellular local levels of plateletderived growth factor subunit B (PDGFB). Data are displayed as box plots with median and 10-90 percentile.

ns $=$ not significance, ${ }^{*} P<0.05, * * P<0.01,{ }^{* * *} P<0.001, * * * * P<0.0001$.

Figure 2. Increased levels of coagulation factors in breast cancer and dense breast tissue A total of 69 women were investigated; 10 breast cancer patients underwent microdialysis before surgery with one catheter inserted into the breast cancer and another into adjacent normal breast tissue and 40 postmenopausal healthy volunteer women, attending the regular mammography-screening program categorized as either having dense $(n=20$, dark green bars) 
or nondense breasts ( $\mathrm{n}=20$, light green bars) and 19 premenopausal women (yellow bars) underwent microdialysis of their left breast. Data represents extracellular local protein abundance in linear values ( $2^{\mathrm{NPX}}$ as described in the Methods section). Kruskal-Wallis followed by Mann Whitney U-test was used for unpaired samples (healthy breast tissues) and Wilcoxon matched-pairs signed-rank for paired samples (breast cancer vs. normal adjacent breast). A. Extracellular local levels of Factor VII (FVII), B. Extracellular local levels of Factor XI (FXI). Data are displayed as box plots with median and $10-90$ percentile. $* * P<0.01$.

\section{Figure 3. Increased levels of fibrinolysis components in breast cancers and dense breast tissue}

A total of 69 women were investigated; 10 breast cancer patients underwent microdialysis before surgery with one catheter inserted into the breast cancer and another into adjacent normal breast tissue and 40 postmenopausal healthy volunteer women, attending the regular mammography-screening program categorized as either having dense $(n=20$, dark green bars) or nondense breasts $(\mathrm{n}=20$, light green bars) and 19 premenopausal women (yellow bars) underwent microdialysis of their left breast. Data represents extracellular local protein abundance in linear values ( $2^{\mathrm{NPX}}$ as described in the Methods section). Kruskal-Wallis followed by Mann Whitney U-test was used for unpaired samples (healthy breast tissues) and Wilcoxon matched-pairs signed-rank for paired samples (breast cancer vs. normal adjacent breast). A. Extracellular local levels of vitamin K-dependent protein C (PROC), B. Extracellular local levels of plasma serine protease inhibitor 5 (SERPINA5), C. Extracellular local levels of tissue factor pathway inhibitor (TFPI), D. Extracellular local levels of Tissue plasminogen activator (tPA), E. Extracellular local levels of Urokinase-type plasminogen activator (uPA), F. Extracellular local levels of plasminogen activator inhibitor 1 (PAI), G. Extracellular local levels of soluble urokinase plasminogen activator receptor (suPAR). Data are displayed as box plots with median and 10-90 percentile. 
ns $=$ not significance, $* P<0.05, * * P<0.01, * * * P<0.001, * * * * P<0.0001$.

655

656 Figure 4. Correlations between inflammatory mediators and coagulation factors in normal 657 human breast tissue in situ

658 A total 42 postmenopausal healthy volunteer women, attending the regular mammography659 screening program and 19 healthy premenopausal women underwent microdialysis of their left 660 breast for sampling of extracellular proteins in vivo. Proteins were quantified using a multiplex 661 proximity extension assay as described in the Methods section. Interleukin (IL), transforming 662 growth factor beta (TGF- $\beta$ ), vascular endothelial growth factor (VEGF), von Willebrand's 663 factor (VWF), proteinase-activated receptor 1 (PAR1), P-selectin, soluble CD40 ligand 664 (CD40L), Platelet-derived growth factor subunit A (PDGFA), Platelet-derived growth factor 665 subunit B (PDGFB), Factor VII (FVII), Factor XI (FXI), tissue factor pathway inhibitor (TFPI),

666 vitamin K-dependent protein C (PROC), tissue plasminogen activator (tPA), urokinase-type 667 plasminogen activator (UPA), soluble urokinase plasminogen activator receptor (suPAR), 668 plasminogen activator inhibitor 1 (PAI), plasma serine protease inhibitor 5 (SERPINA5). Bars 669 represent Spearman's Rank correlation coefficient. White bars, not significant; $* P<0.05$, 670 $* * P<0.01, * * * P<0.001, * * * * P<0.0001$.

672 Figure 5. Correlations between matrix metalloproteinases (MMPs) and coagulation factors in 673 normal human breast tissue in situ

674 A total 42 postmenopausal healthy volunteer women, attending the regular mammography675 screening program and 19 healthy premenopausal women underwent microdialysis of their left 676 breast for sampling of extracellular proteins in vivo. Proteins were quantified using a multiplex 677 proximity extension assay as described in the Methods section. Matrix metalloproteinases 678 (MMP), von Willebrand's factor (VWF), proteinase-activated receptor 1 (PAR1), P-selectin, 
679 soluble CD40 ligand (CD40L), Platelet-derived growth factor subunit A (PDGFA), Platelet-

680 derived growth factor subunit B (PDGFB), Factor VII (FVII), Factor XI (FXI), tissue factor 681 pathway inhibitor (TFPI), vitamin K-dependent protein C (PROC), tissue plasminogen 682 activator (tPA), urokinase-type plasminogen activator (uPA), soluble urokinase plasminogen 683 activator receptor (suPAR), plasminogen activator inhibitor 1 (PAI), plasma serine protease 684 inhibitor 5 (SERPINA5). Bars represent Spearman's Rank correlation coefficient. White bars, 685 not significant; $* P<0.05, * * P<0.01, * * * P<0.001, * * * * P<0.0001$

686

\section{$687 \quad$ Figure 6.}

688 Correlations between local estradiol levels and coagulation factors in abdominal subcutaneous

689 fat and normal human breast tissue in situ

690 A total 42 postmenopausal healthy volunteer women, attending the regular mammography691 screening program and 19 healthy premenopausal women underwent microdialysis of their left 692 breast and abdominal subcutaneous for sampling of extracellular proteins and estradiol in vivo. 693 Proteins and estradiol (E2) were quantified as described in the Methods section. von 694 Willebrand's factor (VWF), proteinase-activated receptor 1 (PAR1), P-selectin, soluble CD40 695 ligand (CD40L), Platelet-derived growth factor subunit A (PDGFA), Platelet-derived growth 696 factor subunit B (PDGFB), Factor VII (FVII), Factor XI (FXI), tissue factor pathway 697 inhibitor (TFPI), vitamin K-dependent protein C (PROC), tissue plasminogen activator (tPA), 698 urokinase-type plasminogen activator (uPA), soluble urokinase plasminogen activator receptor 699 (suPAR), plasminogen activator inhibitor 1 (PAI), plasma serine protease inhibitor 5 700 (SERPINA5).

701 A. Correlations between local levels of estradiol (E2) and proteins in abdominal subcutaneous 702 fat.

703 B. Correlations between local levels of estradiol (E2) and proteins in normal breast tissue. 
704 Bars represent Spearman's Rank correlation coefficient. White bars, not significant; $* P<0.05$, $* * P<0.01, * * * P<0.001, * * * * P<0.0001$

C. Platelets were isolated and exposed to estradiol (E2) \pm progesterone $(\mathrm{P})$ or without hormones

707 (Control) and activated with thrombin and the release of proteins was quantified as described

708 in the materials and methods. uPA was not detectable. PROC is mainly produced in the liver 709 and was therefore not analyzed.

$710 * P<0.05$ compared to control, Student's t-test.

711 Figure 7. Coagulation-inflammation loop in breast tissues with varying densities

712 Nondense breast tissue (left) consists mainly of adipose tissue and low levels of inflammatory 713 cytokines, MMPs and factors released from activated platelets. Dense breast tissue (right) on

714 the other hand comprise higher amounts of collagen, stromal tissue and less adipose tissue and 715 increased levels of inflammatory cytokines, MMPs and factors released from activated 716 platelets. Higher breast density triggers the coagulation system; high abundance of pro717 angiogenic factors increase the vascular permeability allowing platelets to mechanosense the 718 increased stiffness, which in turn triggers the release of factors contained in the platelet granules 719 starting a procoagulant cascade and recruitment of inflammatory cells to the site. In concert with other cell types in the tissue including immune cells, this will lead to an inflammatory 721 cascade that creates an inflammation-coagulation cycle. Persistent inflammation and platelet activation will further promote tissue remodeling and fibrosis resulting in a pro-tumorigenic microenvironment. Less inflammation-coagulation interactions are present in nondense breast

724 tissue because concentrations of the various factors are lower. Thus, if atypical cells arise in the 725 breast epithelium, the microenvironment in dense breasts will be more permissive for continued growth and invasion and subsequent development into clinically significant breast cancer. 
Table 1. Levels of extracellular proteins in microdialysis samples from subcutaneous abdominal fat tissue in postmenopausal women with dense or nondense breast tissue and premenopausal women. Median values (25-75 percentiles).

\begin{tabular}{lllll}
$\begin{array}{llll}\text { Protein } \\
\left(2^{\mathrm{NPX}}\right)\end{array}$ & $\begin{array}{l}\text { Nondense } \\
(n=20)\end{array}$ & $\begin{array}{l}\text { Dense } \\
(n=19)\end{array}$ & $\begin{array}{l}\text { Premenopausal } \\
(n=22)\end{array}$ & $\begin{array}{l}P \text {-value } \\
\text { Kruskal-Wallis }\end{array}$ \\
\hline PDGFA & $7.7(4.6-12.6)$ & $10(6.6-16)$ & $18(7-38)$ & 0.1 \\
PDGFB & $2.9(1.7-6.7)$ & $3.5(1.9-6.8)$ & $5.1(2-12)$ & 0.3 \\
PAR1 & $1.7(1.5-2.1)$ & $2(1.7-2.6)$ & $1.7(1.4-2.7)$ & 0.2 \\
CD40L & $38(17-45)$ & $46(36-55)$ & $42(27-73)$ & 0.3 \\
P-Selectin & $4.7(3-11)$ & $5.5(4.7-21)$ & $20(3.9-34)$ & 0.1 \\
uPA & $122(54-264)$ & $201(113-327)$ & $675(306-1049)$ & $<0.0001$ \\
PAI & $74(33-146)$ & $128(66-194)$ & $168(82-651)$ & 0.04 \\
suPAR & $1413(1019-2769)$ & $2013(1419-2966)$ & $3852(1943-5727)$ & 0.01 \\
tPA & $37(15-118)$ & $94(32-142)$ & $54(17-79)$ & 0.2 \\
FVII & $76(40-165)$ & $144(64-220)$ & $160(88-226)$ & 0.1 \\
VWF & $28(11-82)$ & $38(25-69)$ & $70(31-133)$ & 0.1 \\
FXI & $17(4-32)$ & $23(8-79)$ & $46(15-93)$ & 0.1 \\
SERPINA5 & $1828(1478-1991)$ & $1896(1733-2031)$ & $1053(836-1334)$ & $<0.0001$ \\
TFPI & $267(142-349)$ & $343(191-416)$ & $305(160-546)$ & 0.3 \\
PROC & $18(4-53)$ & $36(19-61)$ & $67(42-116)$ & 0.01
\end{tabular}
CD40 ligand (CD40L), Platelet-derived growth factor subunit A (PDGFA), Platelet-derived growth factor subunit B(PDGFB), Factor VII (FVII), Factor XI (FXI), tissue factor pathway inhibitor (TFPI), vitamin K-dependent protein C (PROC), tissue plasminogen activator (tPA), urokinase-type plasminogen activator (uPA), soluble urokinase plasminogen activator receptor (suPAR), plasminogen activator inhibitor 1 (PAI), plasma serine protease inhibitor 5 736 (SERPINA5). 

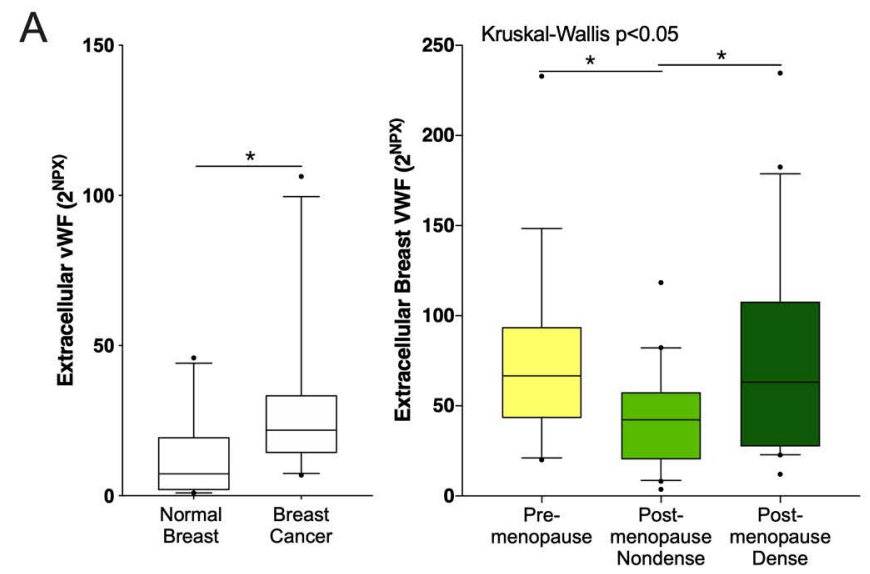

C
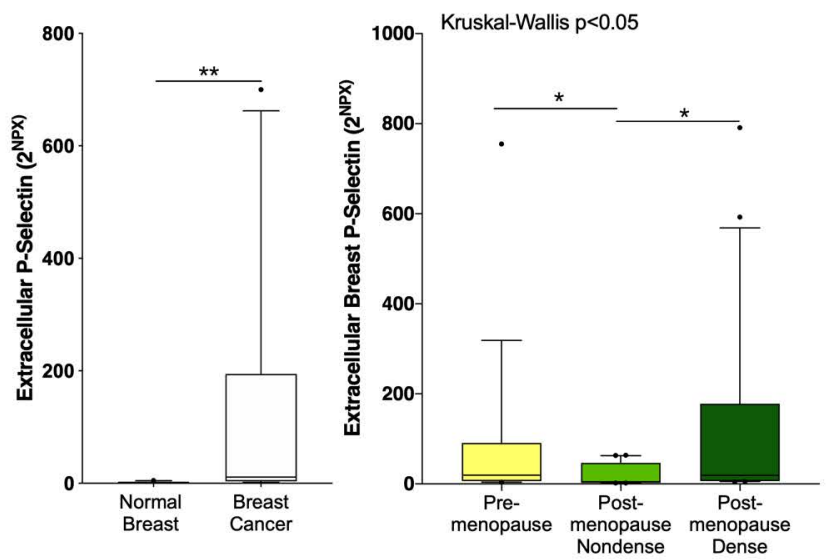

E
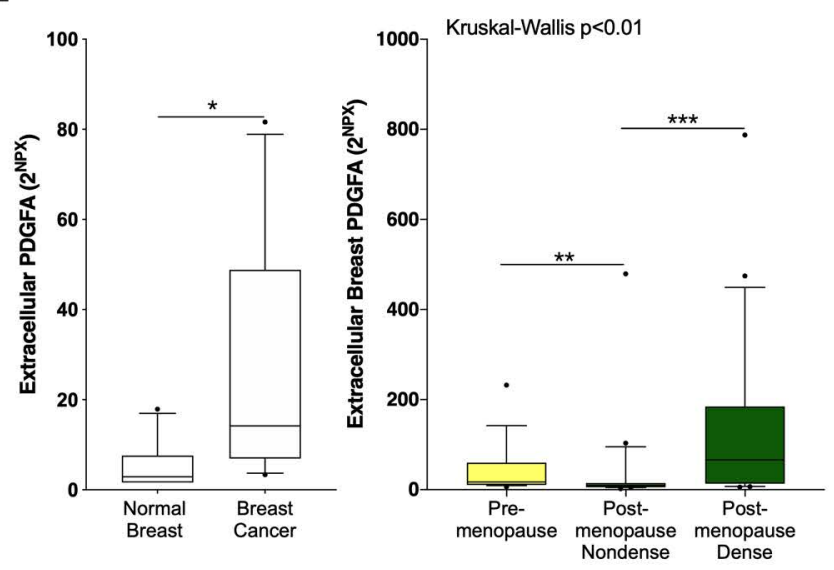

B
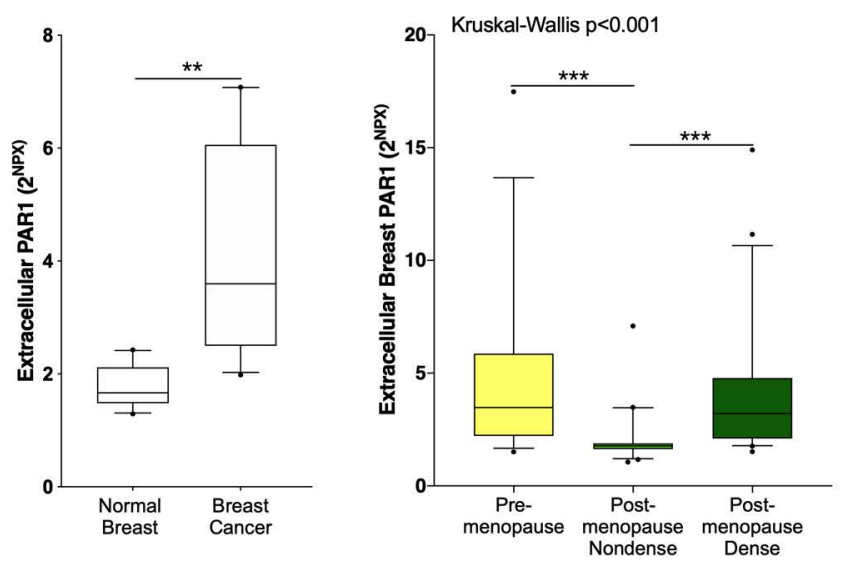

D
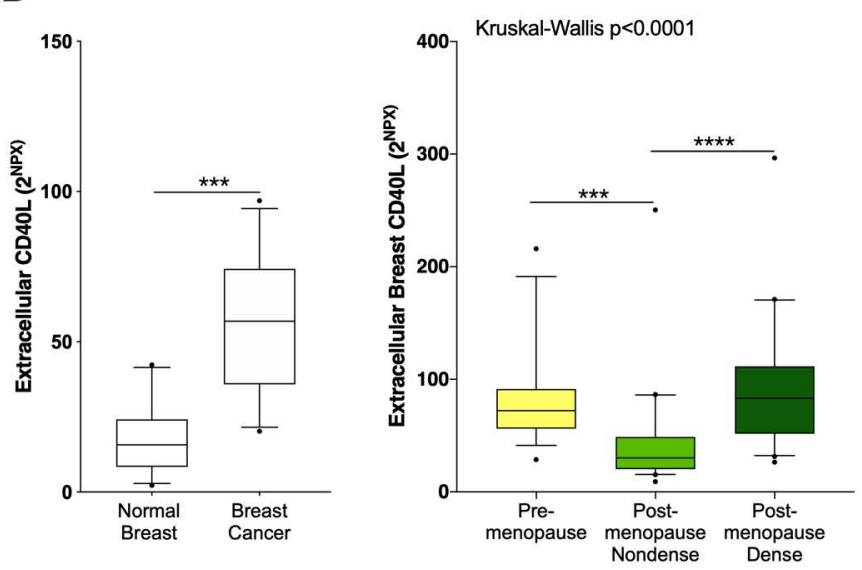

F
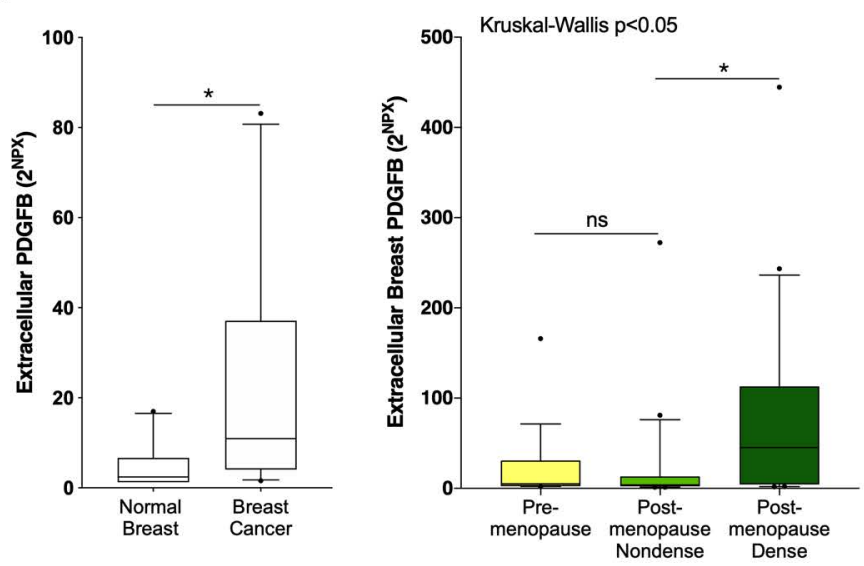
A

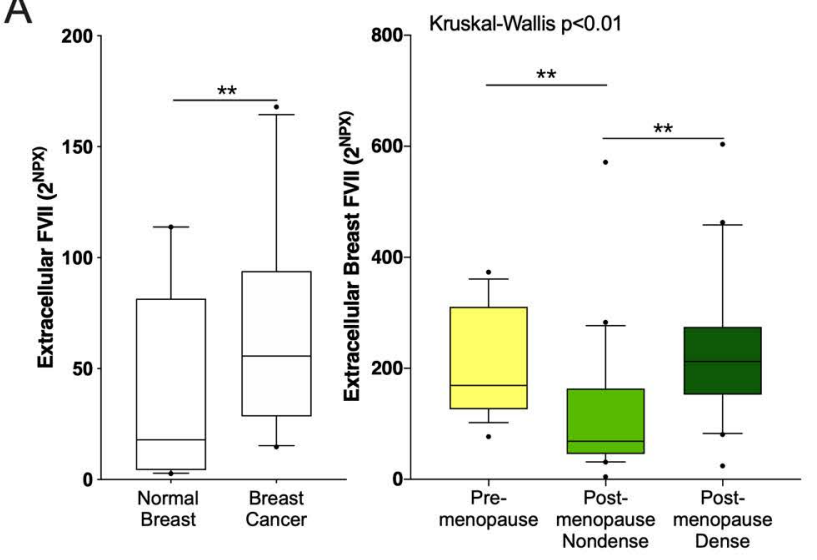

B

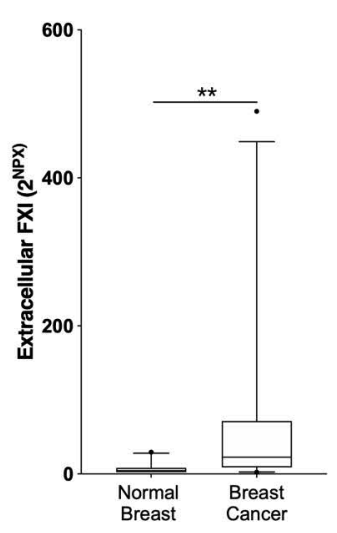

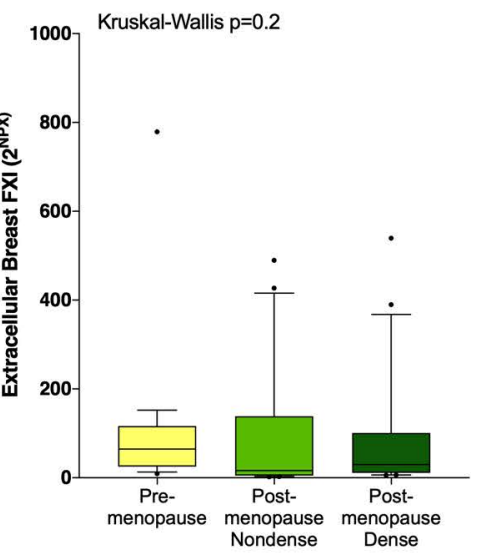



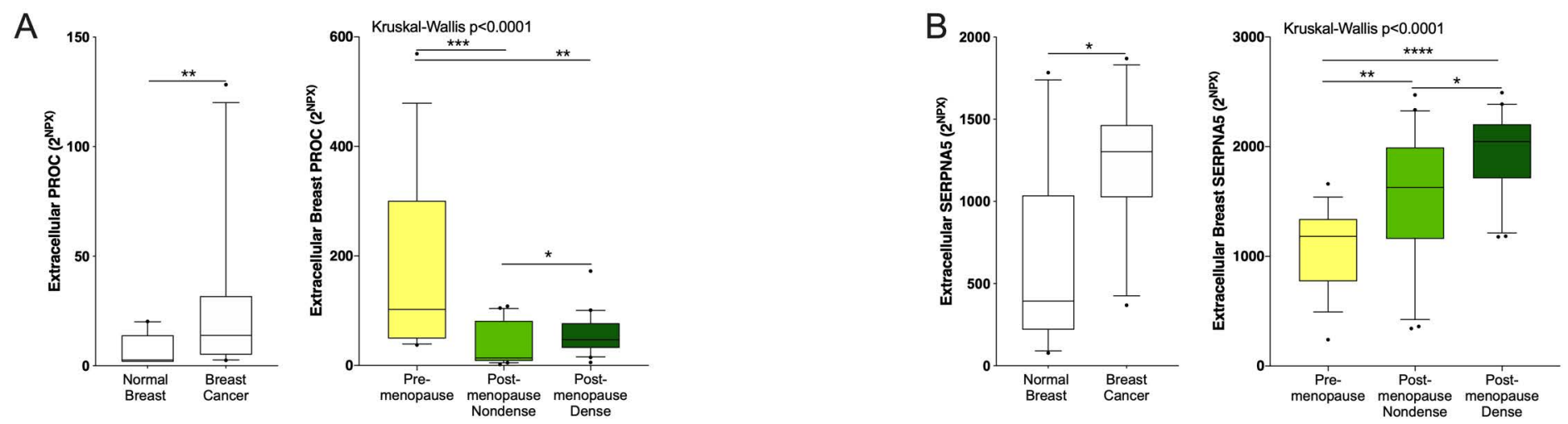

C
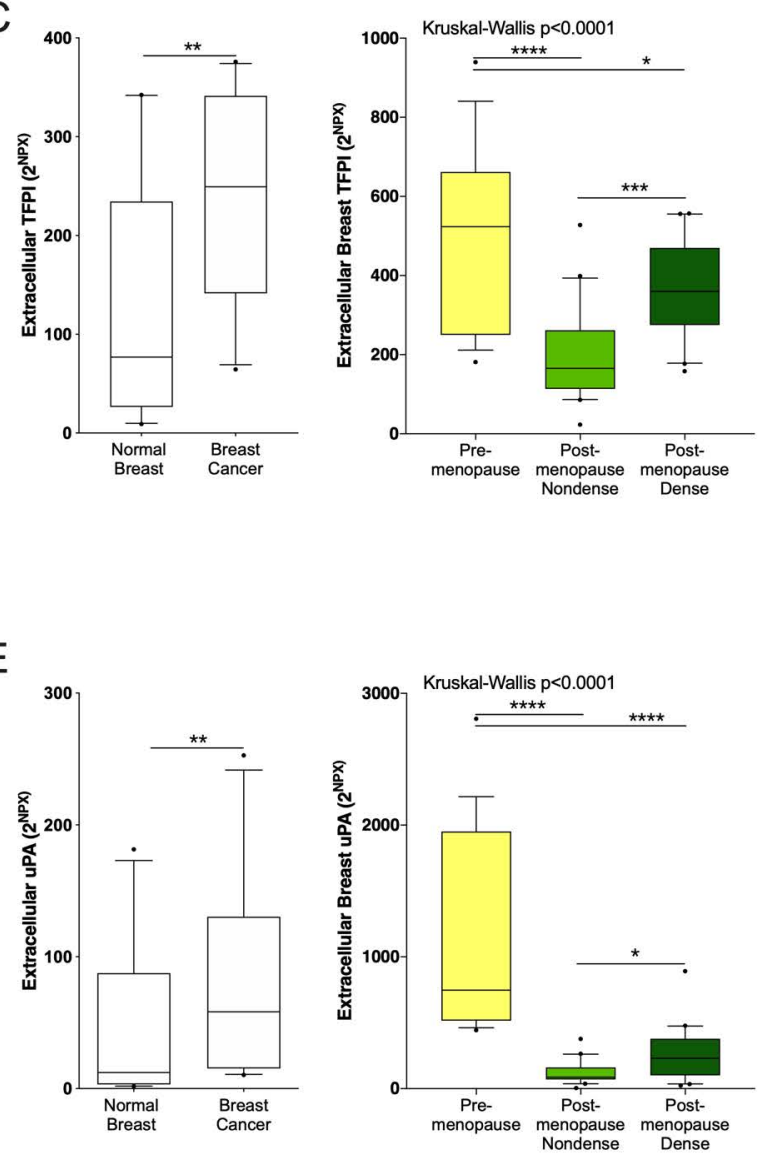

G
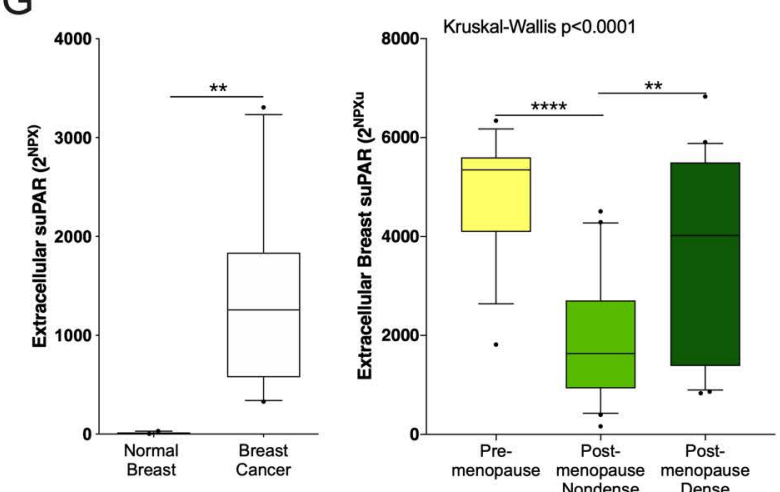
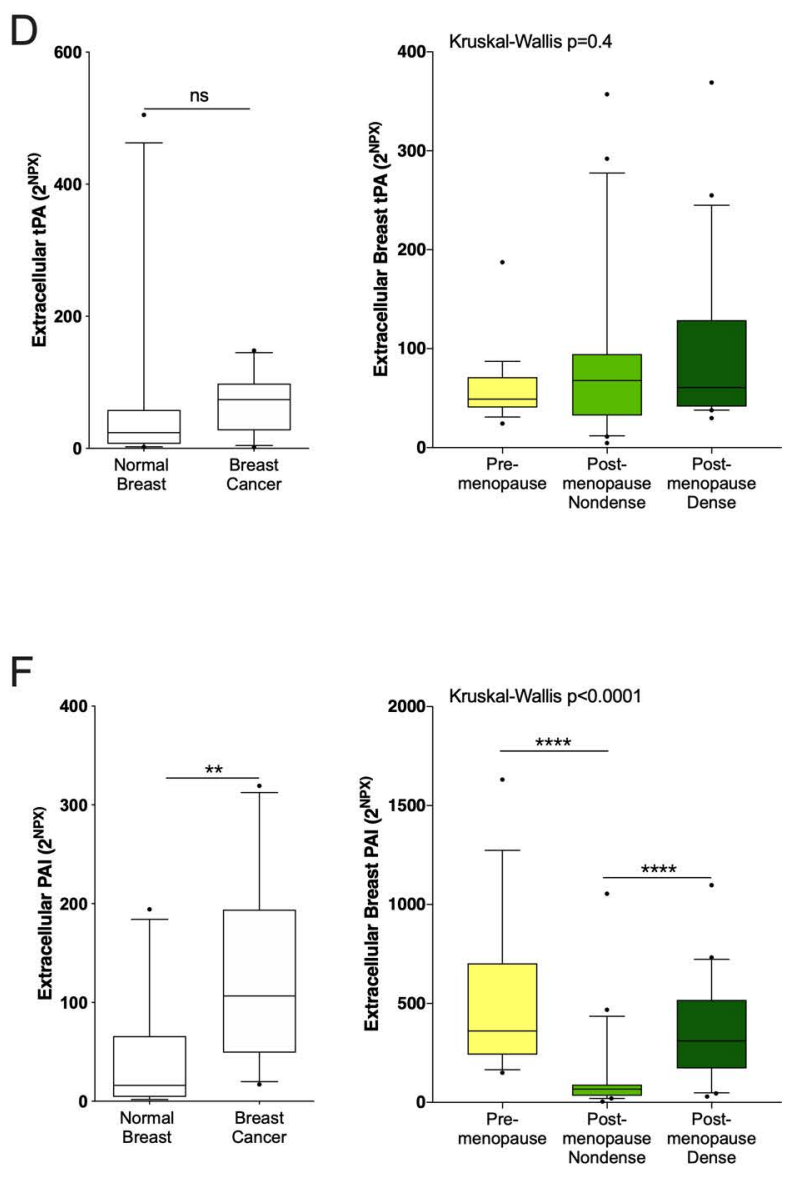
Correlations with IL-6

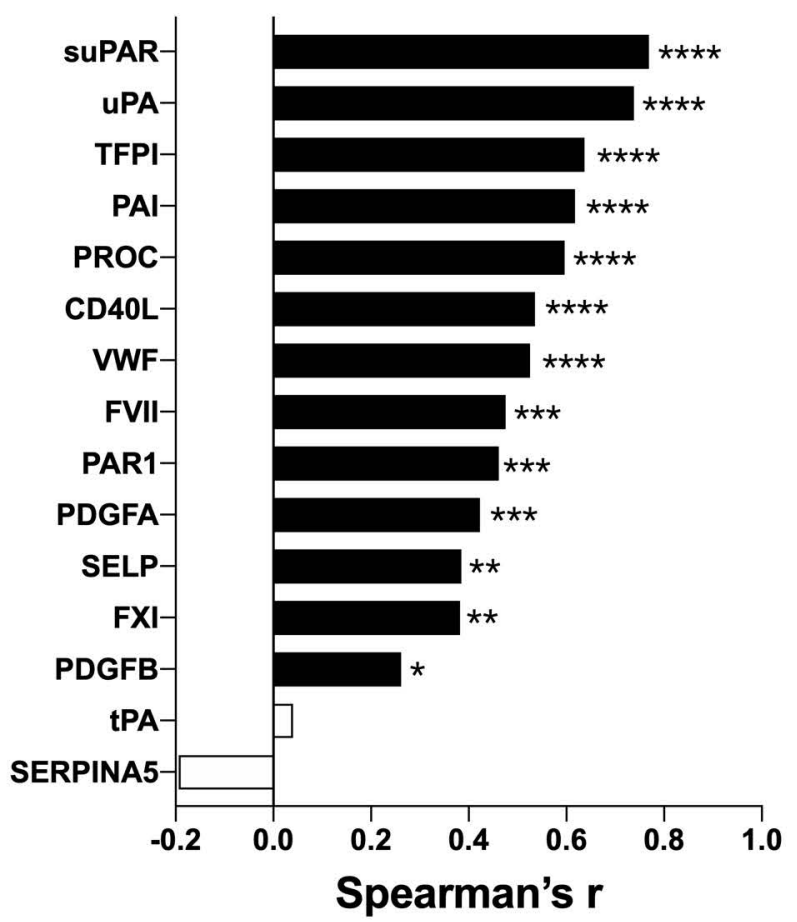

Correlations with TGF- $\beta$

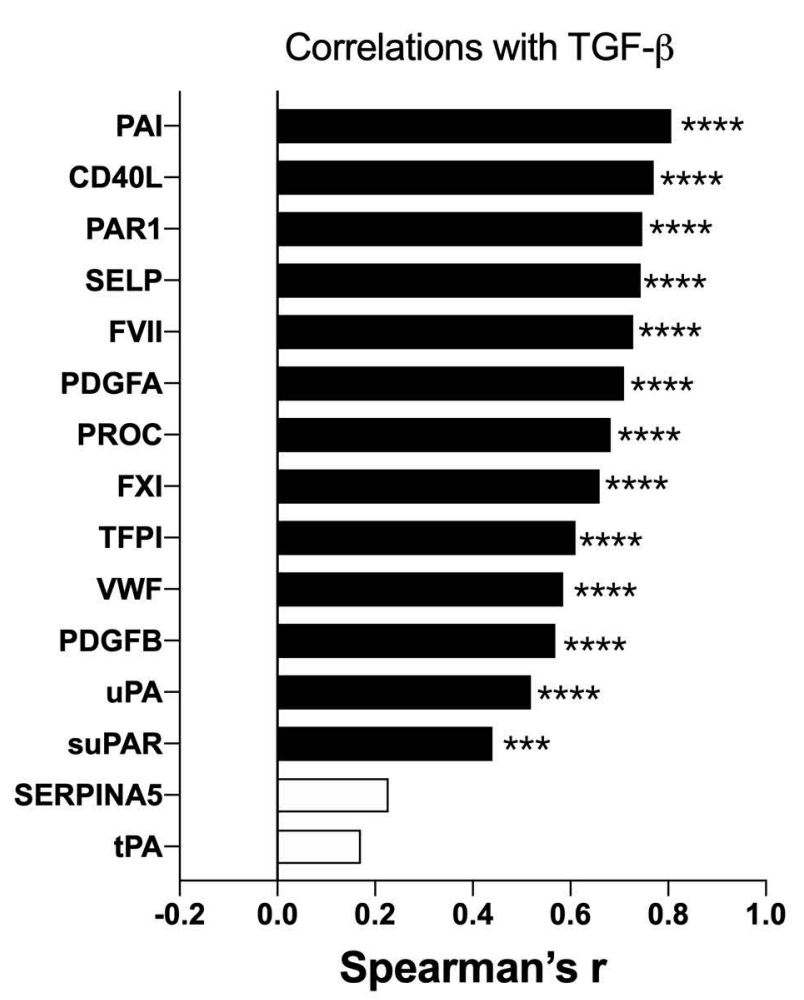

Correlations with IL-8

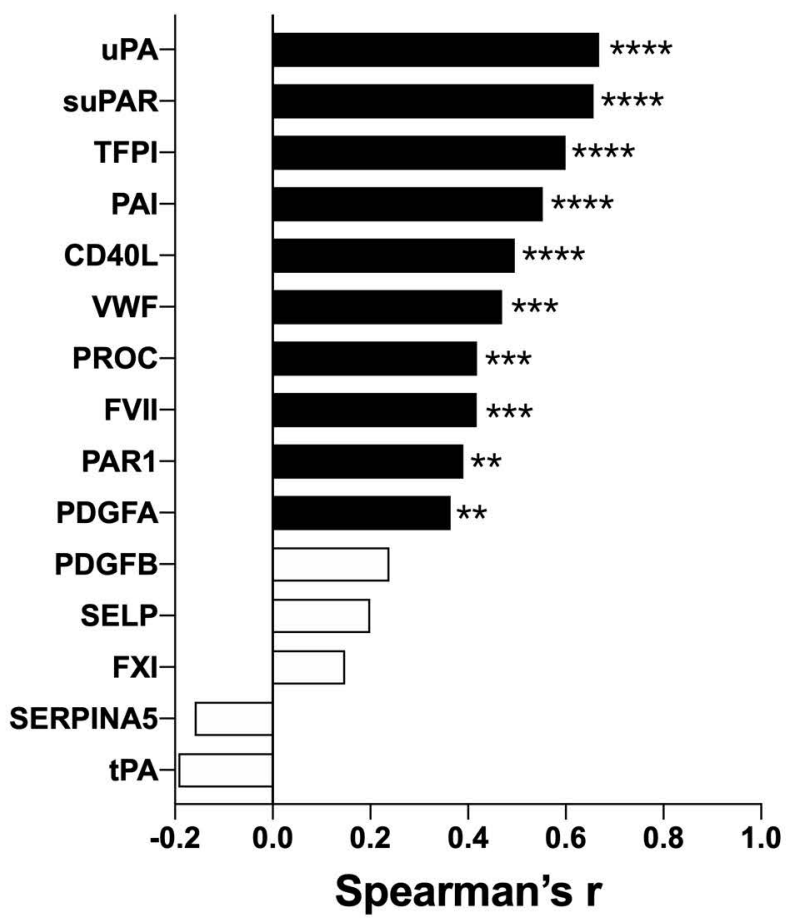

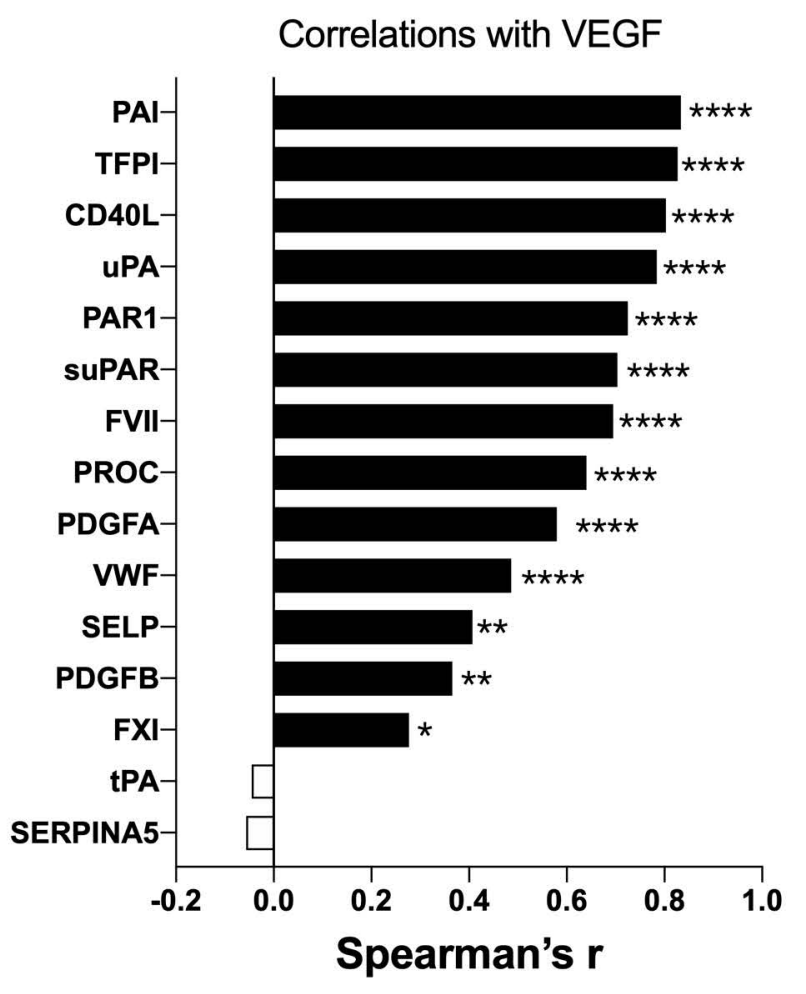


Correlations with MMP-1

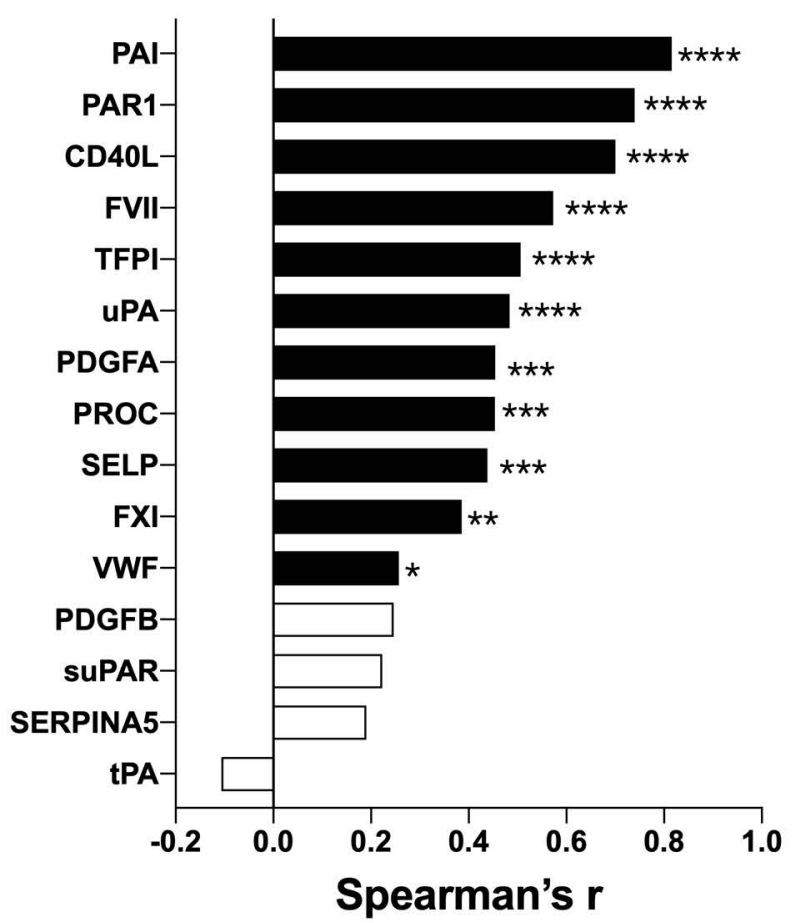

Correlations with MMP-2

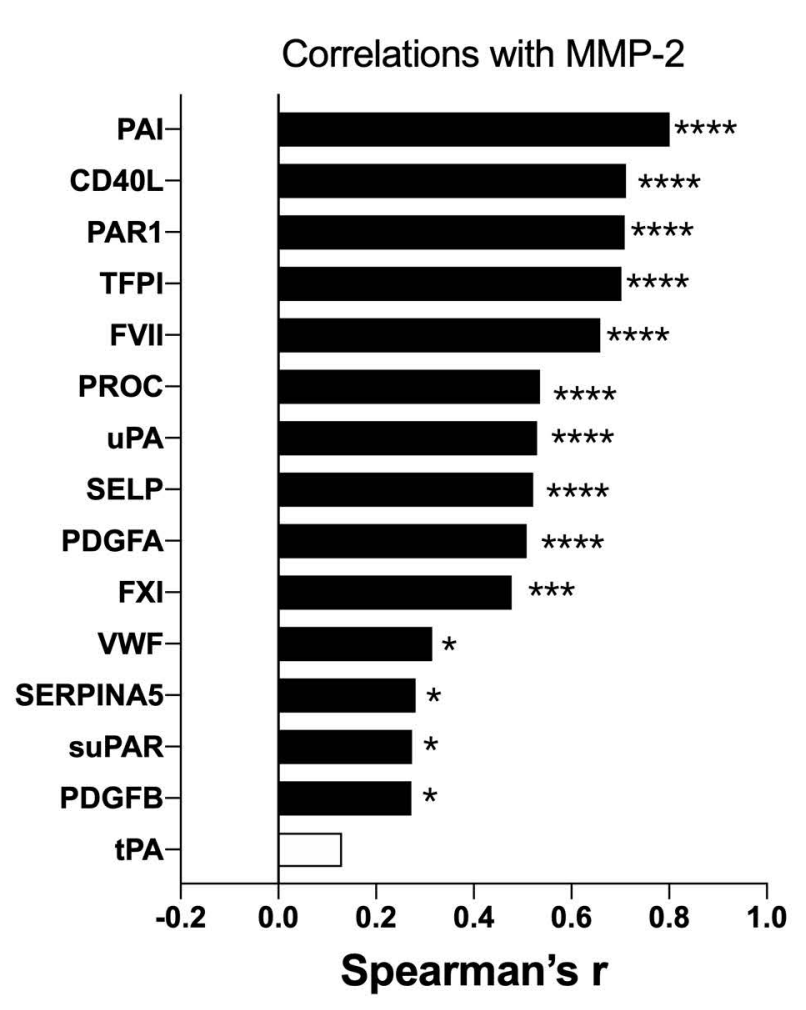

Correlations with MMP-2

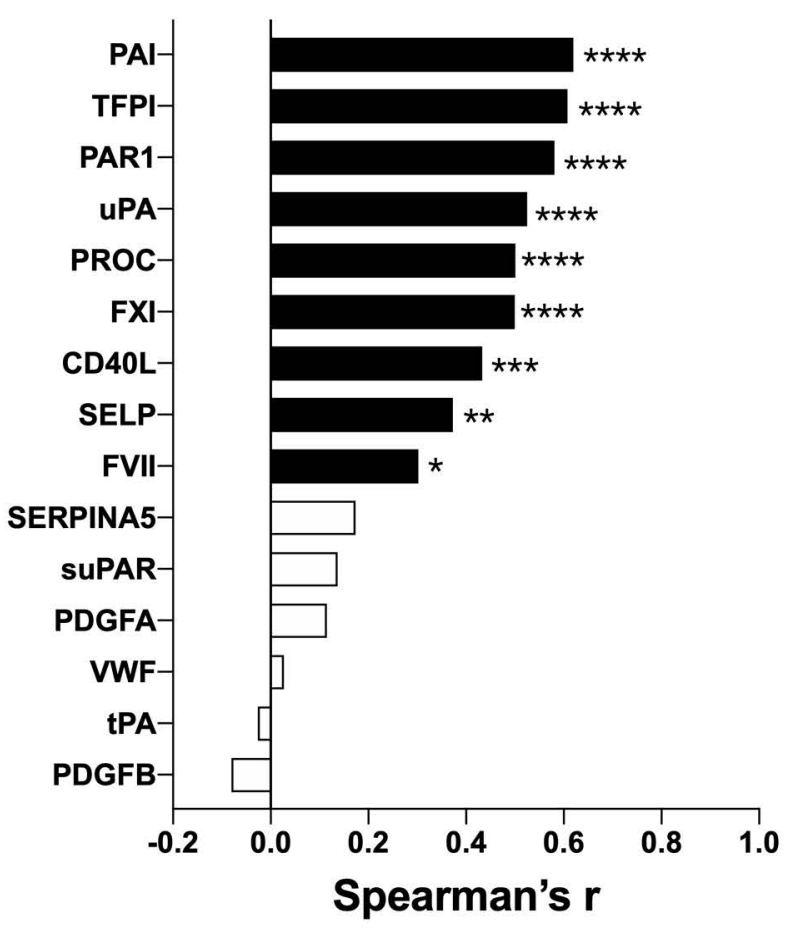

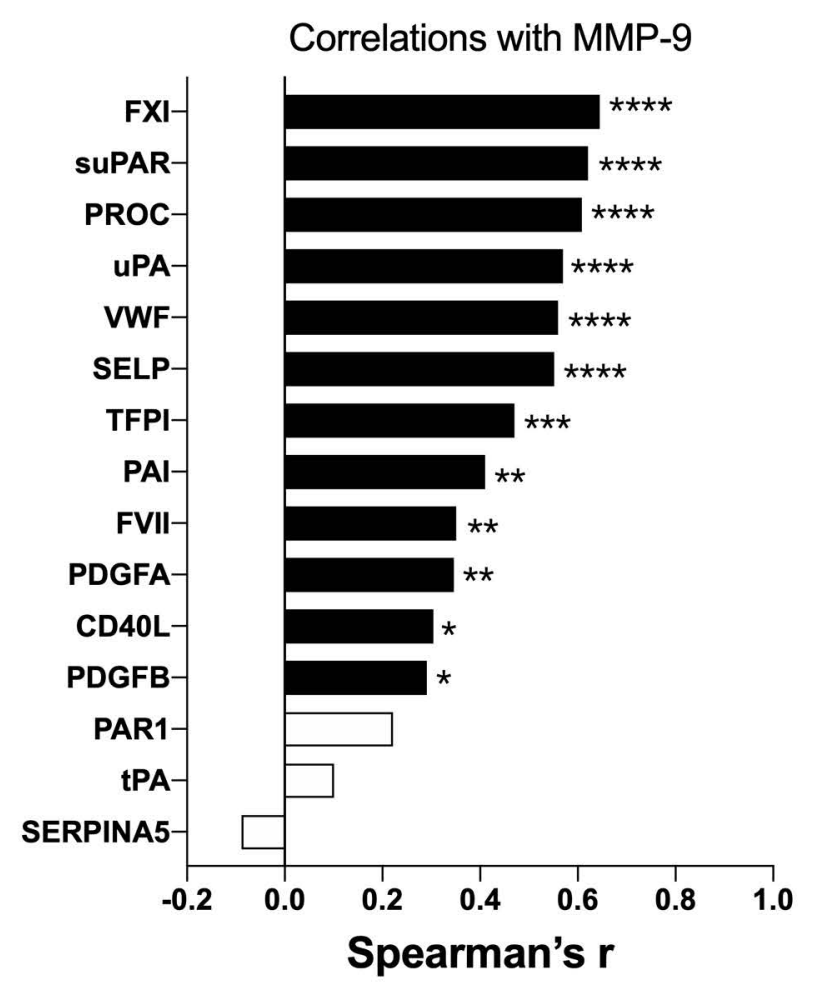




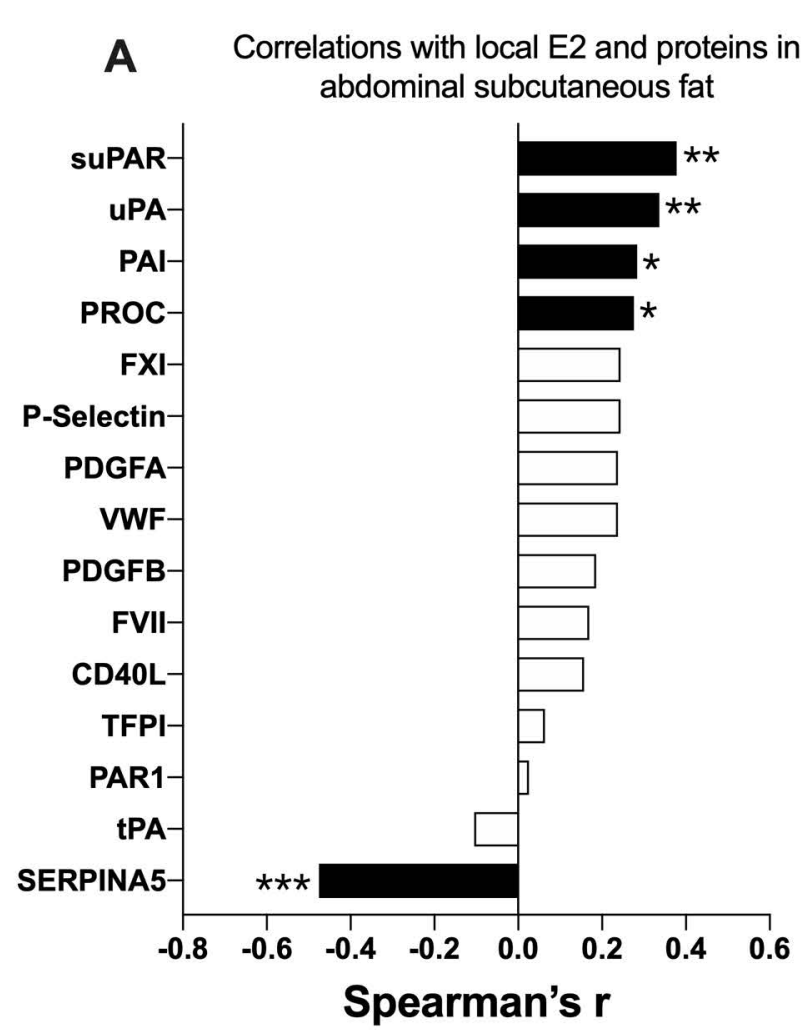

B

Correlations with local E2 and proteins in breast tissue

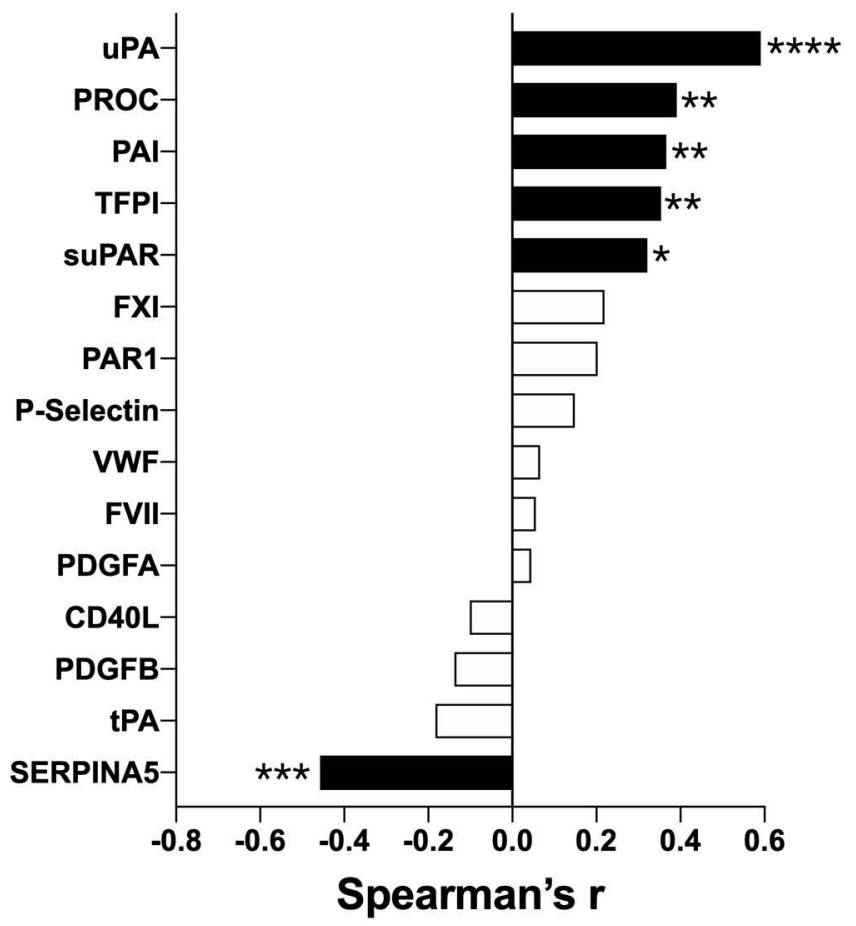

C
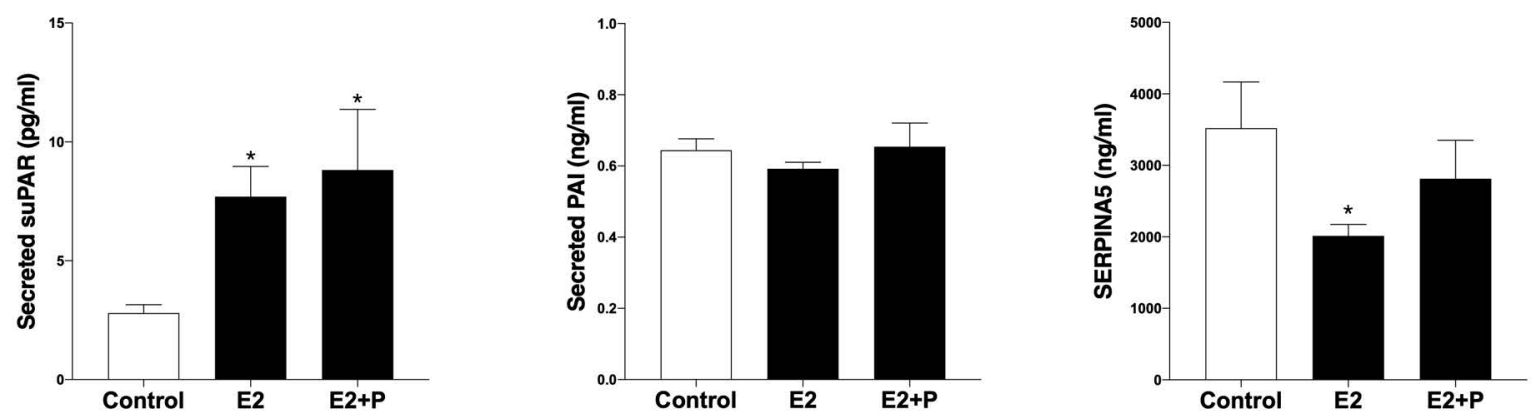


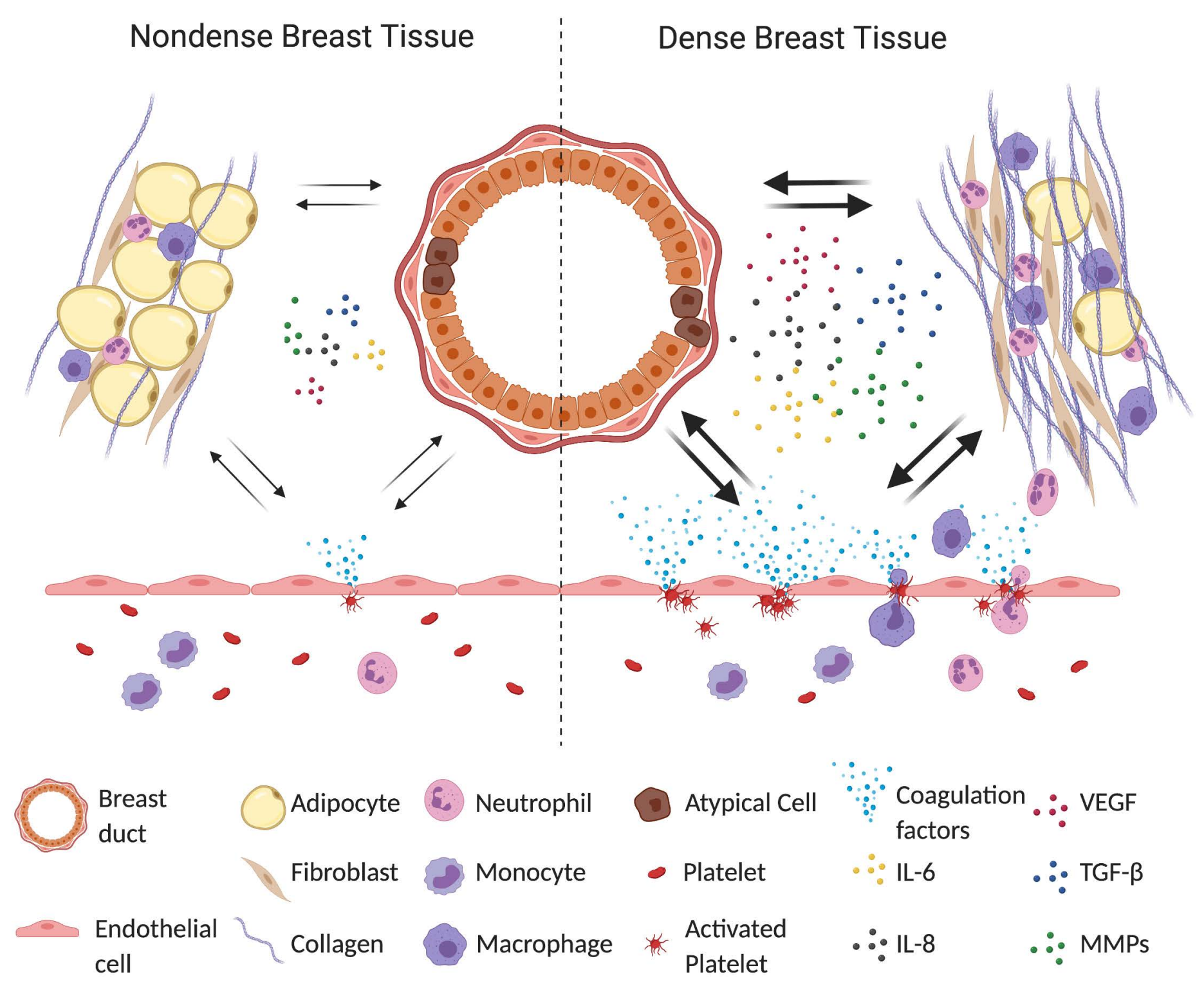

